\title{
The impact of the COVID-19 pandemic on maternal and perinatal health: a scoping review
}

Bethany Kotlar ${ }^{1}$, Emily Michelle Gerson², Sophia Petrillo ${ }^{3}$, Ana Langer ${ }^{1}$ and Henning Tiemeier ${ }^{1,4^{*}}$ (1)

\begin{abstract}
Introduction The Covid-19 pandemic affects maternal health both directly and indirectly, and direct and indirect effects are intertwined. To provide a comprehensive overview on this broad topic in a rapid format behooving an emergent pandemic we conducted a scoping review.

Methods A scoping review was conducted to compile evidence on direct and indirect impacts of the pandemic on maternal health and provide an overview of the most significant outcomes thus far. Working papers and news articles were considered appropriate evidence along with peer-reviewed publications in order to capture rapidly evolving updates. Literature in English published from January 1st to September 112020 was included if it pertained to the direct or indirect effects of the COVID-19 pandemic on the physical, mental, economic, or social health and wellbeing of pregnant people. Narrative descriptions were written about subject areas for which the authors found the most evidence.
\end{abstract}

Results The search yielded 396 publications, of which 95 were included. Pregnant individuals were found to be at a heightened risk of more severe symptoms than people who are not pregnant. Intrauterine, vertical, and breastmilk transmission were unlikely. Labor, delivery, and breastfeeding guidelines for COVID-19 positive patients varied. Severe increases in maternal mental health issues, such as clinically relevant anxiety and depression, were reported. Domestic violence appeared to spike. Prenatal care visits decreased, healthcare infrastructure was strained, and potentially harmful policies implemented with little evidence. Women were more likely to lose their income due to the pandemic than men, and working mothers struggled with increased childcare demands.

Conclusion Pregnant women and mothers were not found to be at higher risk for COVID-19 infection than people who are not pregnant, however pregnant people with symptomatic COVID-19 may experience more adverse outcomes compared to non-pregnant people and seem to face disproportionate adverse socio-economic consequences. High income and low- and middle-income countries alike faced significant struggles. Further resources should be directed towards quality epidemiological studies.

Plain English summary The Covid-19 pandemic impacts reproductive and perinatal health both directly through infection itself but also indirectly as a consequence of changes in health care, social policy, or social and economic circumstances. The direct and indirect consequences of COVID-19 on maternal health are intertwined. To provide a comprehensive overview on this broad topic we conducted a scoping review. Pregnant women who have symptomatic COVID-19 may experience more severe outcomes than people who are not pregnant. Intrauterine and

\footnotetext{
*Correspondence:

Henning Tiemeier

tiemeier@hsph.harvard.edu

Full list of author information is available at the end of the article
}

\section{$\triangle B M C$} International License, which permits use, sharing, adaptation, distribution and reproduction in any medium or format, as long as you give appropriate credit to the original author(s) and the source, provide a link to the Creative Commons licence, and indicate if changes were made. The images or other third party material in this article are included in the article's Creative Commons licence, unless indicated otherwise in a credit line to the material. If material is not included in the article's Creative Commons licence and your intended use is not permitted by statutory regulation or exceeds the permitted use, you will need to obtain permission directly from the copyright holder. To view a copy of this licence, visit http://creativecommons.org/licenses/by/4.0/. The Creative Commons Public Domain Dedication waiver (http://creativecommons.org/publicdomain/zero/1.0/) applies to the data made available in this article, unless otherwise stated in a credit line to the data. 
breastmilk transmission, and the passage of the virus from mother to baby during delivery are unlikely. The guidelines for labor, delivery, and breastfeeding for COVID-19 positive patients vary, and this variability could create uncertainty and unnecessary harm. Prenatal care visits decreased, healthcare infrastructure was strained, and potentially harmful policies are implemented with little evidence in high and low/middle income countries. The social and economic impact of COVID-19 on maternal health is marked. A high frequency of maternal mental health problems, such as clinically relevant anxiety and depression, during the epidemic are reported in many countries. This likely reflects an increase in problems, but studies demonstrating a true change are lacking. Domestic violence appeared to spike. Women were more vulnerable to losing their income due to the pandemic than men, and working mothers struggled with increased childcare demands. We make several recommendations: more resources should be directed to epidemiological studies, health and social services for pregnant women and mothers should not be diminished, and more focus on maternal mental health during the epidemic is needed.

Keywords COVID-19, SARS-CoV-2, Maternal health, Newborn health, Maternal-child transmission, Mental health, Gender equity

\section{Background}

COVID-19, first documented in Wuhan, China at the end of 2019 [1], has rapidly spread across the globe, infecting tens of millions of individuals [2]. While sex-disaggregated data on severe acute respiratory syndrome coronavirus 2 (SARS-CoV-2) mortalities suggest it poses more severe health outcomes for men than women [3], there are concerns that the disease could disproportionately burden women in a social and economic sense. Furthermore, it is a particularly salient question whether pregnant women are more susceptible to infection with SARS-CoV-2 or have more severe disease outcomes. Outside of direct infection, the impact of the pandemic and pandemic-control policies on healthcare infrastructure, societies, and the global economy may also affect maternal health. Pregnant women and new mothers are a unique population, with particular mental and physical healthcare needs who are also particularly vulnerable to issues such as domestic violence. Finally, the impact of the COVID-19 pandemic is likely to be contextspecific, and differ depending on a variety of country-specific factors. A global pandemic is likely to only reveal its consequences after significant time passes, and literature published before or immediately after policies are implemented may not capture all relevant outcomes. The goal of this scoping review is to synthesize the current literature on both the direct consequences of contracting COVID19 during pregnancy and the indirect consequences of the pandemic for pregnant individuals and mothers, taking into account the myriad ways in which containment and prevention measures have disrupted daily life.

\section{Methods}

This scoping review followed the framework outlined by Arksey and O'Malley [4], in order to map the existing literature on the direct and indirect impacts of COVID19 on maternal health, incorporating the following 5 stages:

\section{Identify research question}

How has the COVID-19 pandemic directly and indirectly impacted maternal health globally?

\section{Identify relevant types of evidence}

Literature published in English from January 1st, 2020 to September 11, 2020 was included in the search. The search strategy involved the algorithm used by the Maternal Health Task Force's Buzz, a biweekly e-newsletter presenting current research relevant to maternal health. Hand searches were conducted in PubMed using $\mathrm{MeSH}$ terms (see Additional file 1), along with broader searches of "COVID" and "corona" followed by the terms: "pregnant", "maternal", "women", "reproductive", "economic", "social", "indirect", "direct." Google Scholar was also searched using these terms to capture grey literature, such as news articles and working papers that have not yet completed the peer review process. This scoping review aimed to capture rapidly evolving evidence in a timely manner, including issues not yet addressed in wellfunded, epidemiological studies. The snowball method of consulting sources' bibliographies was used for certain articles to supplement referenced evidence. The search strategy as outlined above was not registered with PROSPERO.

\section{Study selection}

Literature was included if published during the time frame outlined above and primarily assessed the direct or indirect effects of the COVID-19 pandemic on maternal health. Search terms utilized did not directly address neonatal health, but publications on topics relevant to both populations (transmission, breastfeeding, maternity care practices) were also included if returned by the search terms. Case reports, case series, qualitative studies, systematic and scoping reviews, and meta-analyses 
were included. As some publications included were systematic or scoping reviews or meta-analyses, there was some duplication in data on which publications were based. The article containing the more complete description of the data was used for data charting. Sources were excluded if they consisted only of recommendations for future research. Predictive research was excluded if it consisted only of speculation referencing past epidemics but included if based on quantitative methods. News articles, reports, and other grey literature were included if they contained quantifiable evidence (case reports, survey results, qualitative analyses).After reading full texts and synthesizing relevant evidence, literature was organized thematically. Themes were discussed and decided upon by all four authors. Themes that reflected potential impacts of COVID-19, but for which no quantitative evidence existed were excluded from the review. Of 200 peer-reviewed articles, 129 were excluded; 7 did not pertain to maternal health or COVID-19, 3 were responses to articles, and 199 were commentaries, editorials, or practice guidelines which did not contain relevant evidence. Of 196 articles from the grey literature, 172 articles were excluded; 124 did not pertain to maternal health or COVID-19, and 48 did not contain objective information. See Fig. 1 for a visual representation of inclusion and exclusion.

\section{Chart the data}

71 peer-reviewed articles and 24 publications from the grey literature were included from the original search.
Two peer-reviewed articles that contradicted earlier findings that were published after September 11, 2020 were added. Publications included represented a wide range of methodologies including case reports, case series, observational studies, letters to the editor, and news articles. The authors developed a rubric of major themes that arose in the literature and recorded standard information including location, sampling method, and size of sample, and key findings of each study (see Table 1). An adaptive thematic analysis [5] was applied using the following steps. The authors identified themes in the literature by a reading and discussing each article included. Articles were then coded independently by two authors. All four authors discussed each code and grouped codes into final themes.

\section{Collate, summarize, and report results}

Narrative descriptions of the evidence were written for each theme that the authors determined in the above stages. All authors reviewed descriptions for clarity and relevance and some themes were combined post hoc to improve readability and avoid redundancy.

\section{Main text \\ Direct effects on pregnancy}

During pregnancy, people undergo significant physiologic and immunologic alterations to support and protect the developing fetus. These changes can increase the risk of infection with respiratory viruses for pregnant individuals and their fetuses. Thus, pregnant individuals

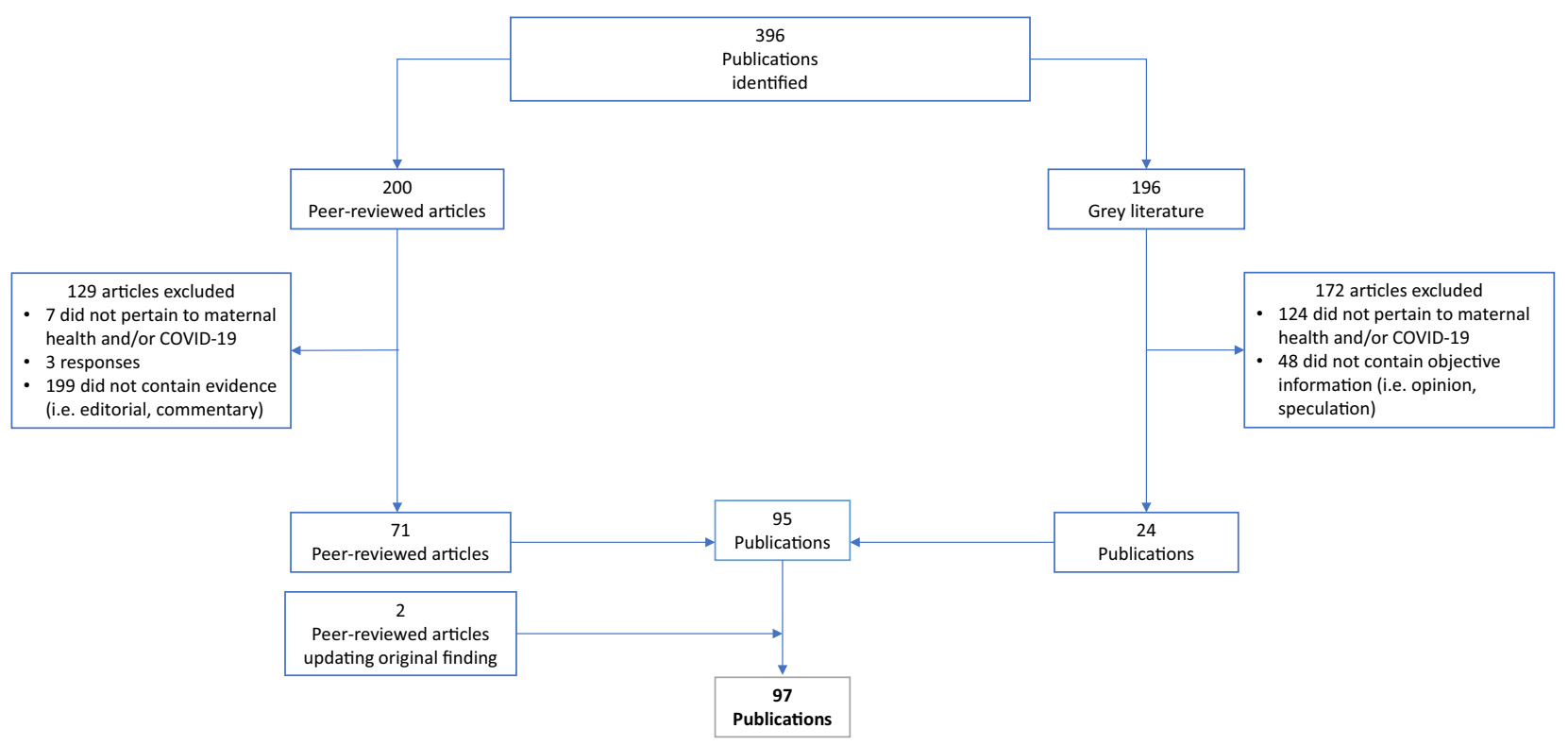

Fig. 1 Flowchart of literature selection 


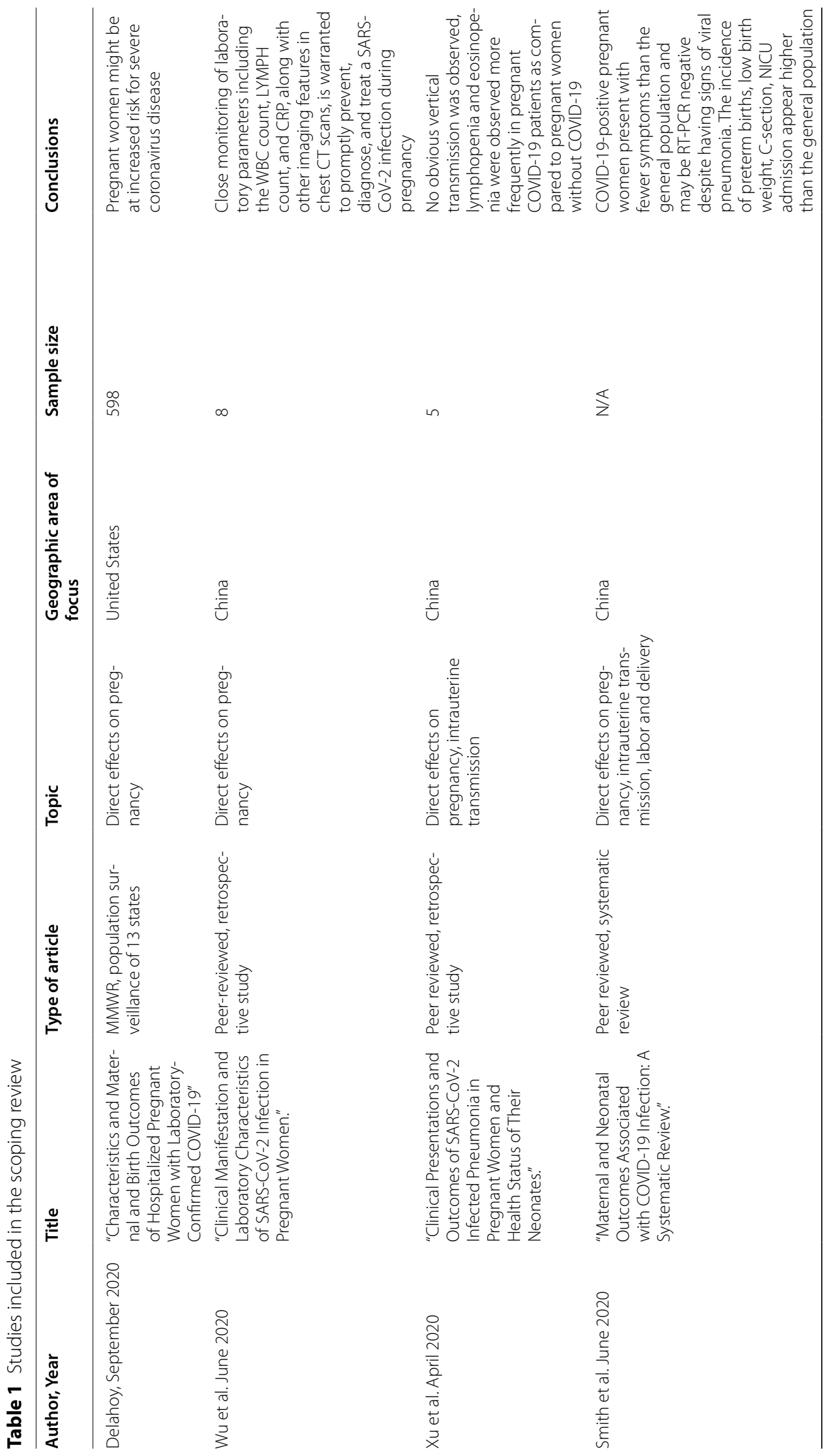




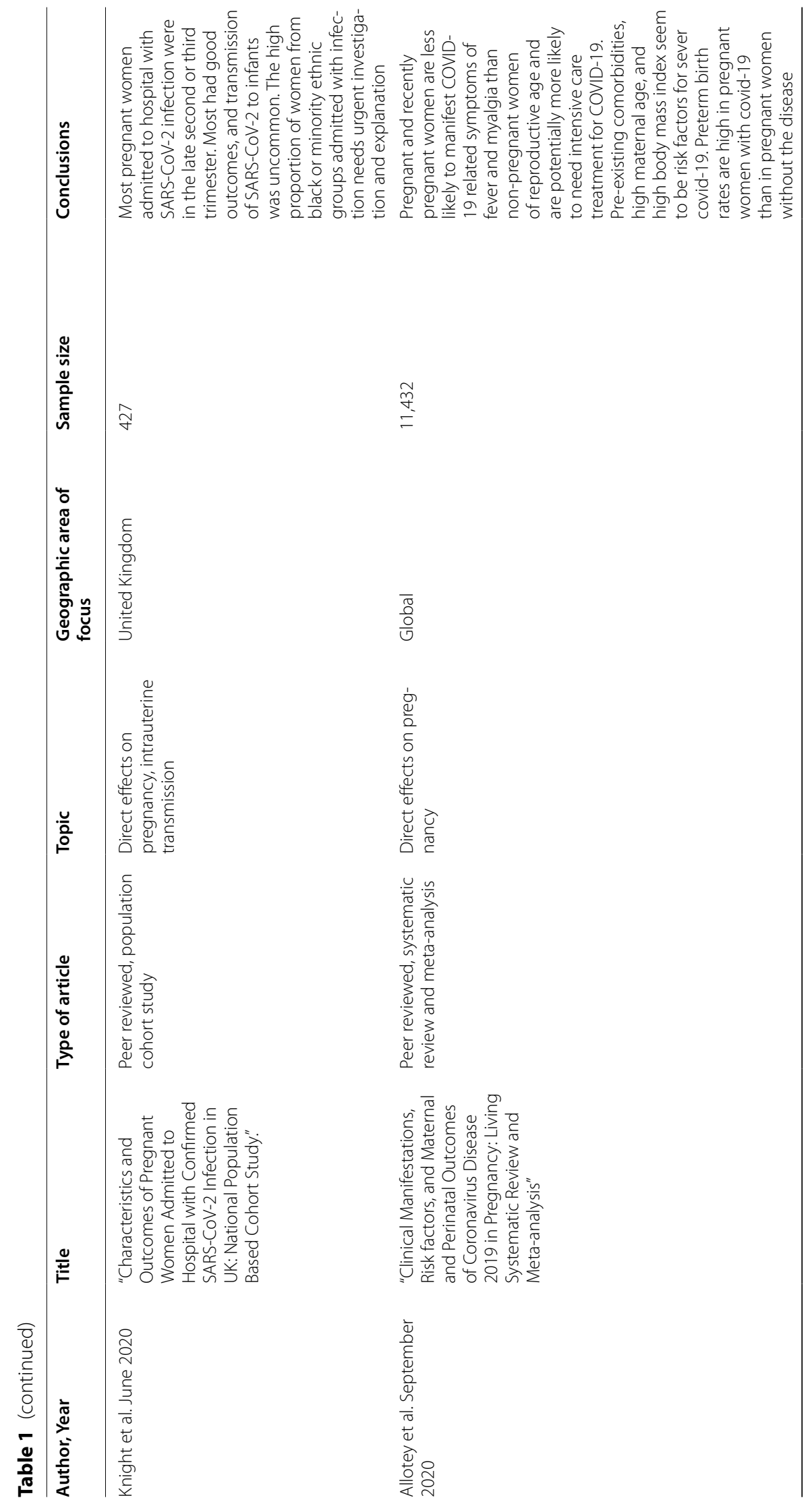




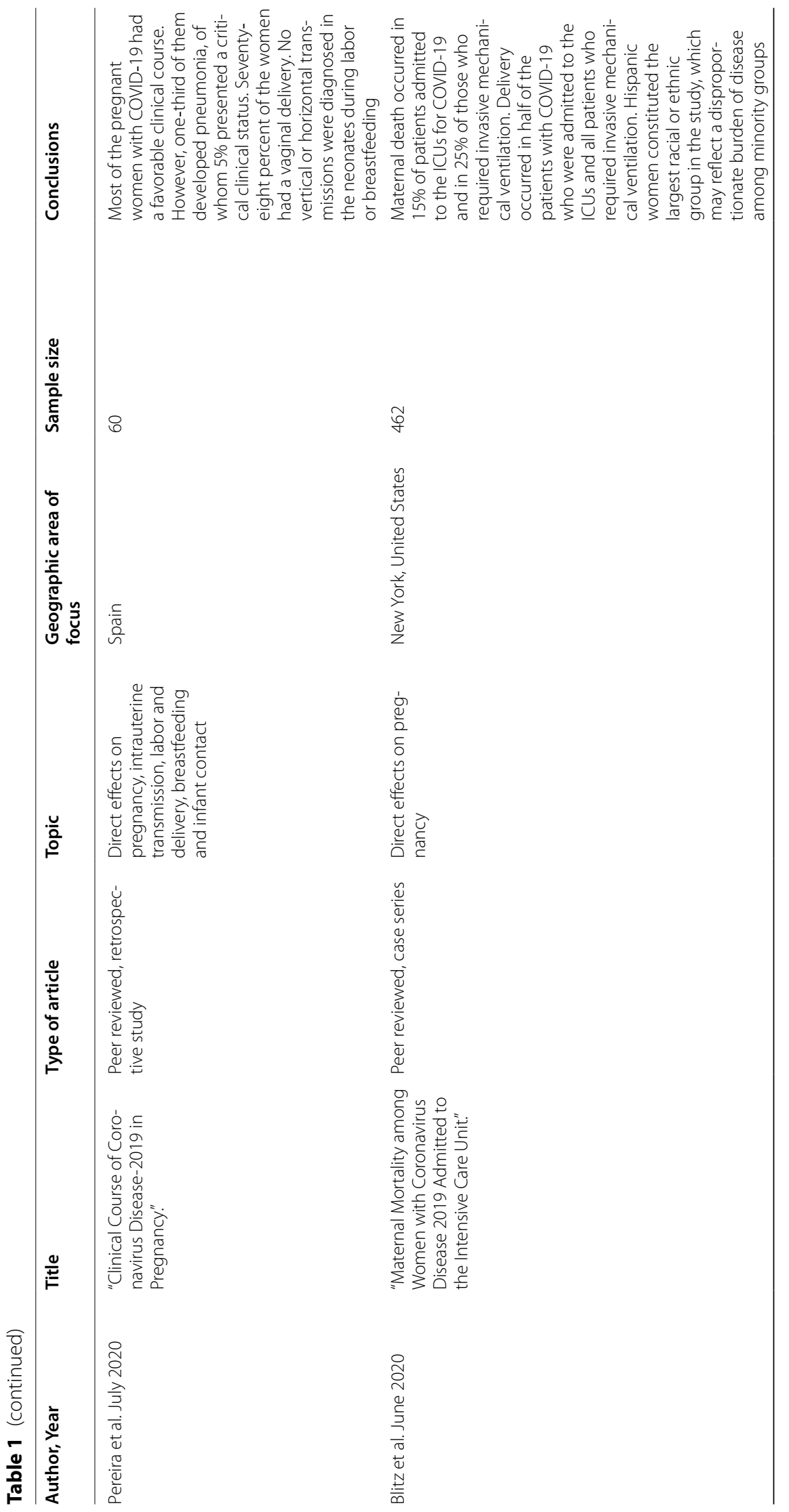




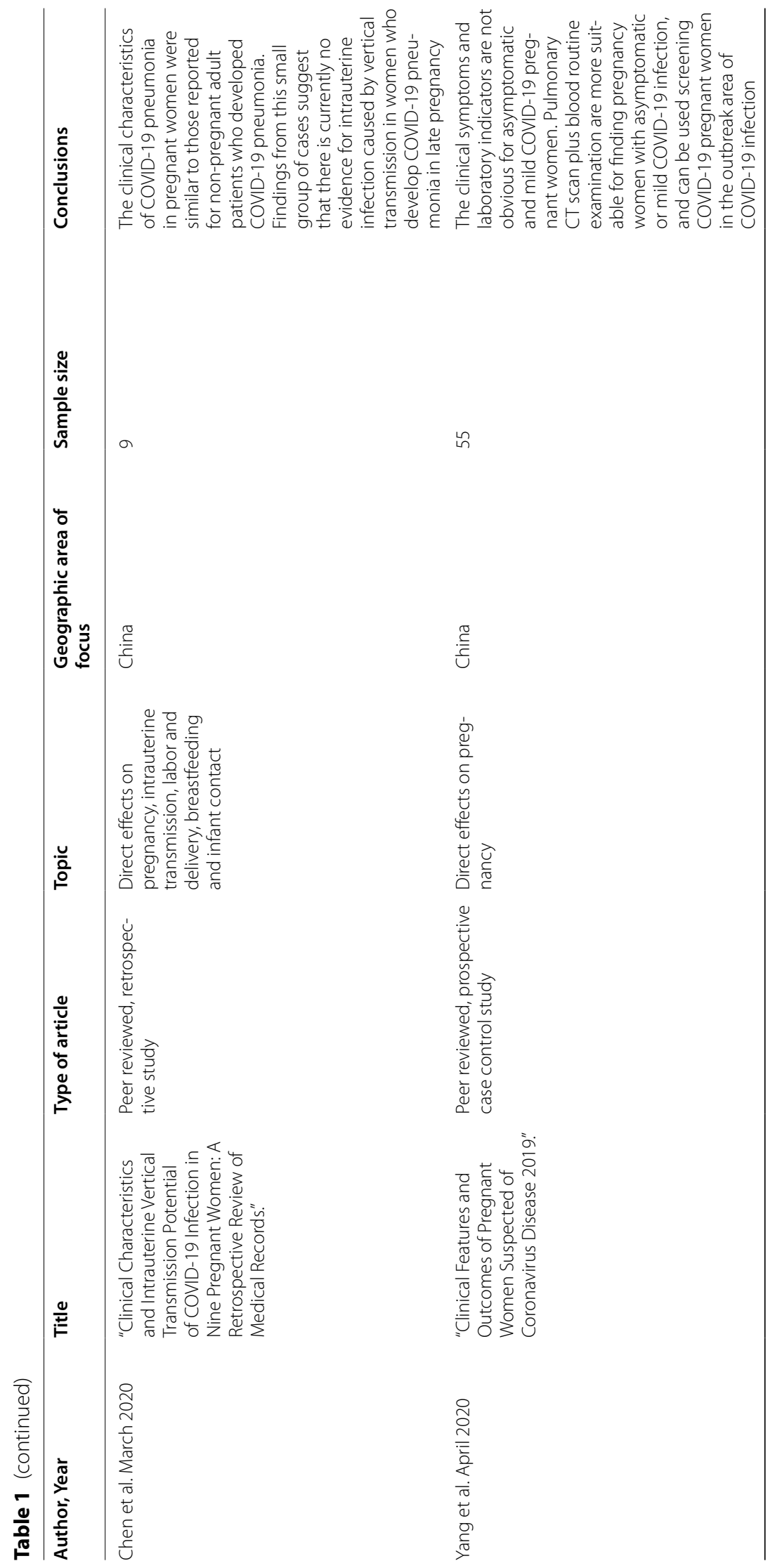




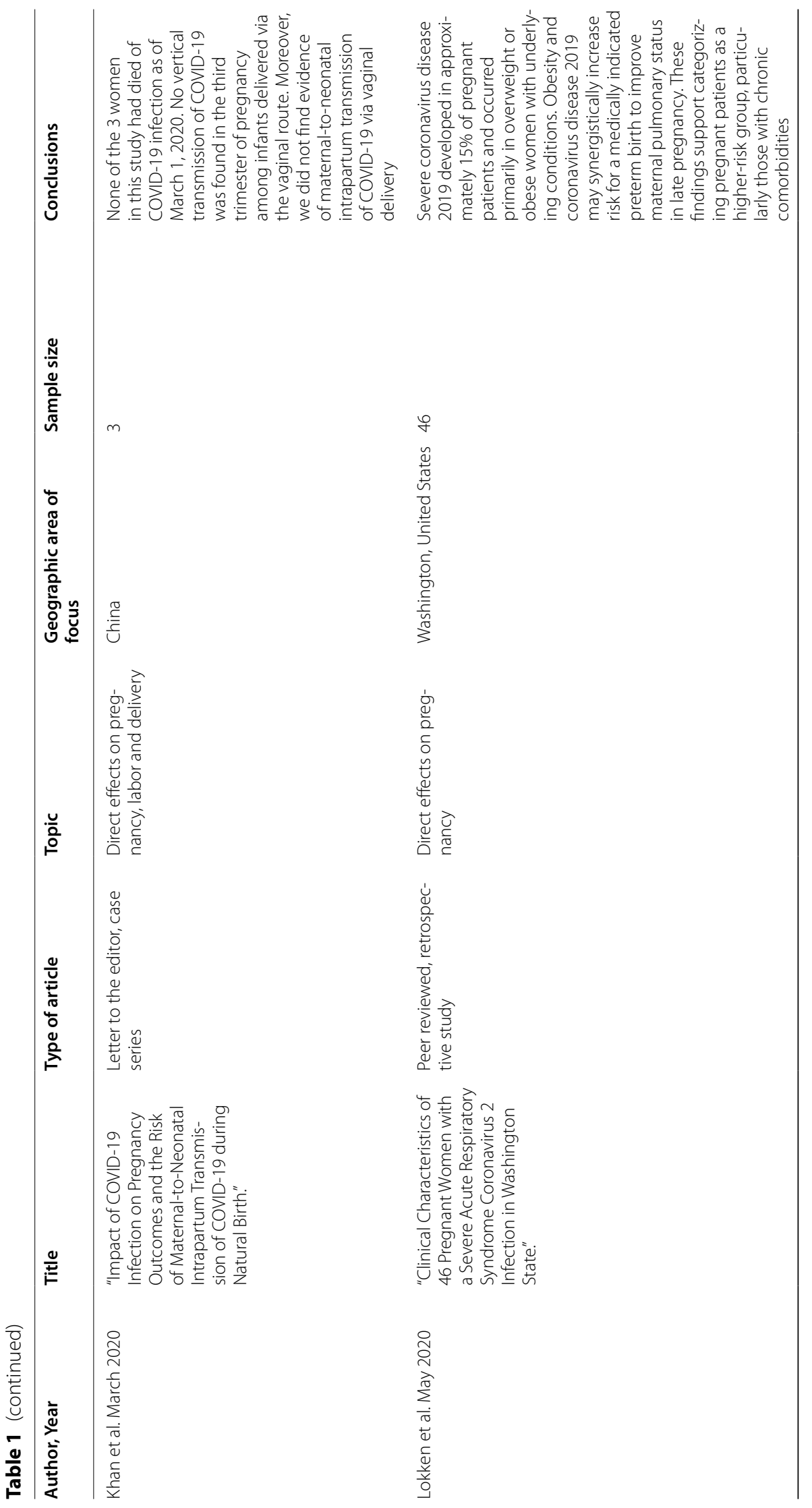




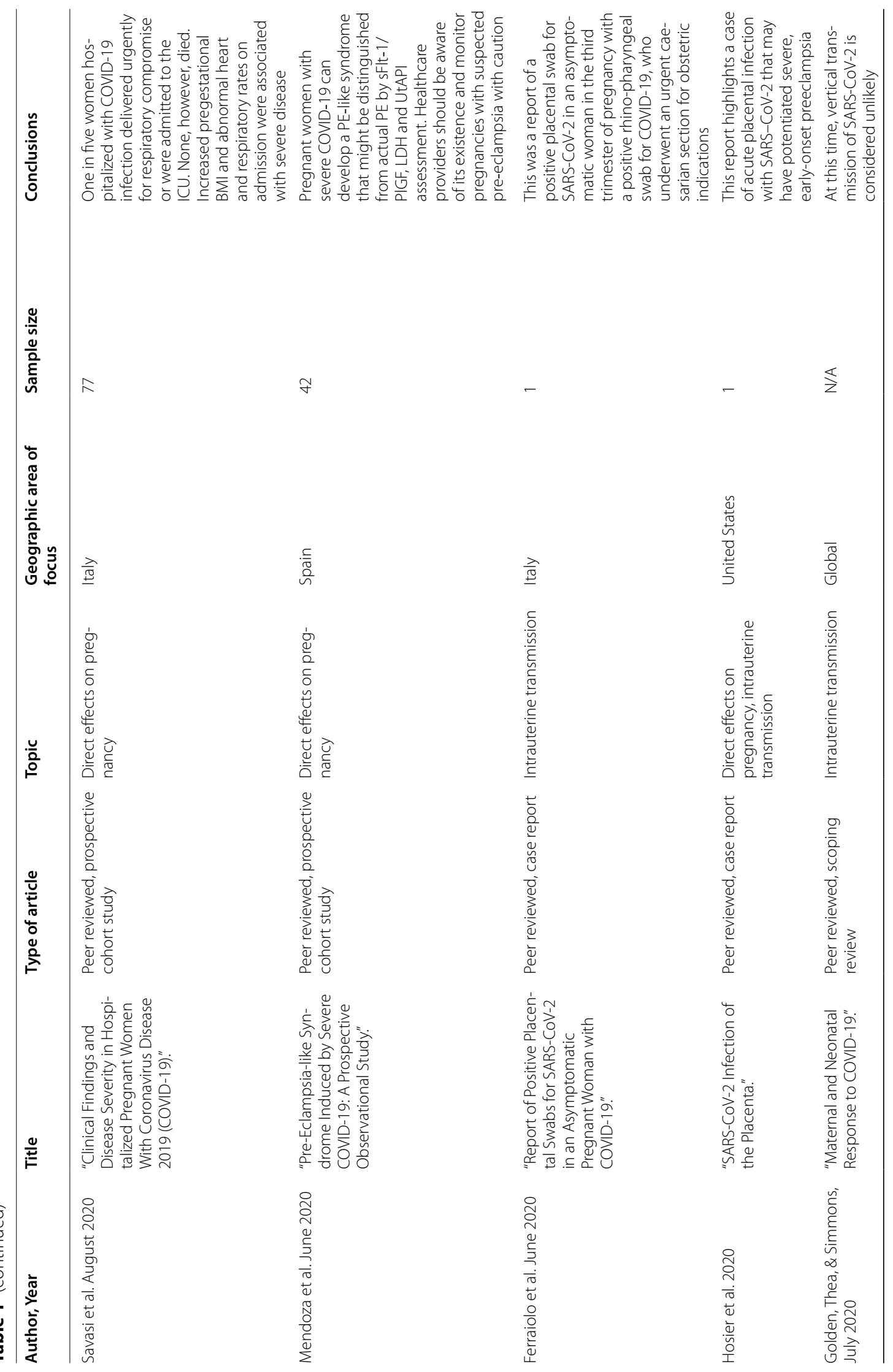




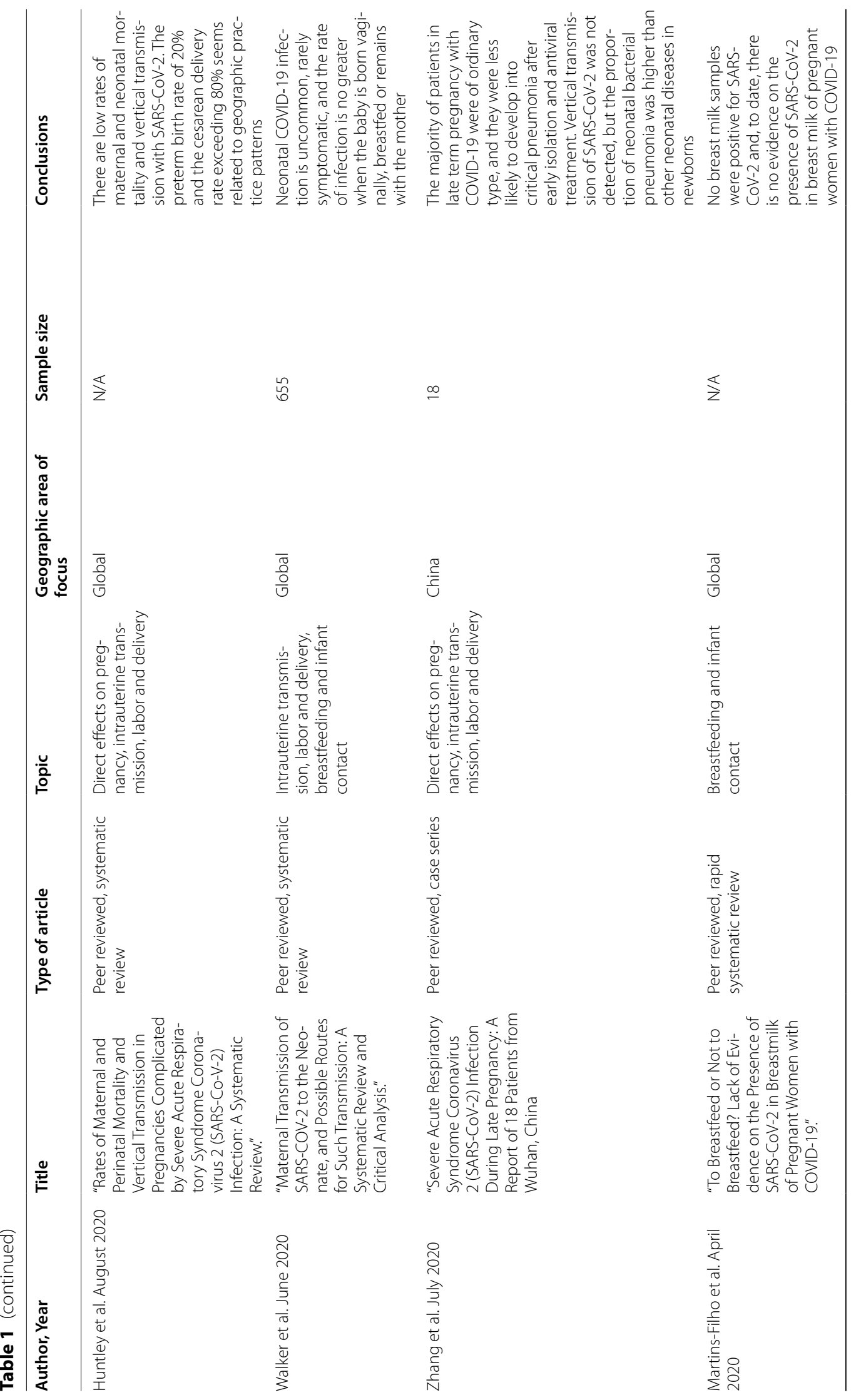




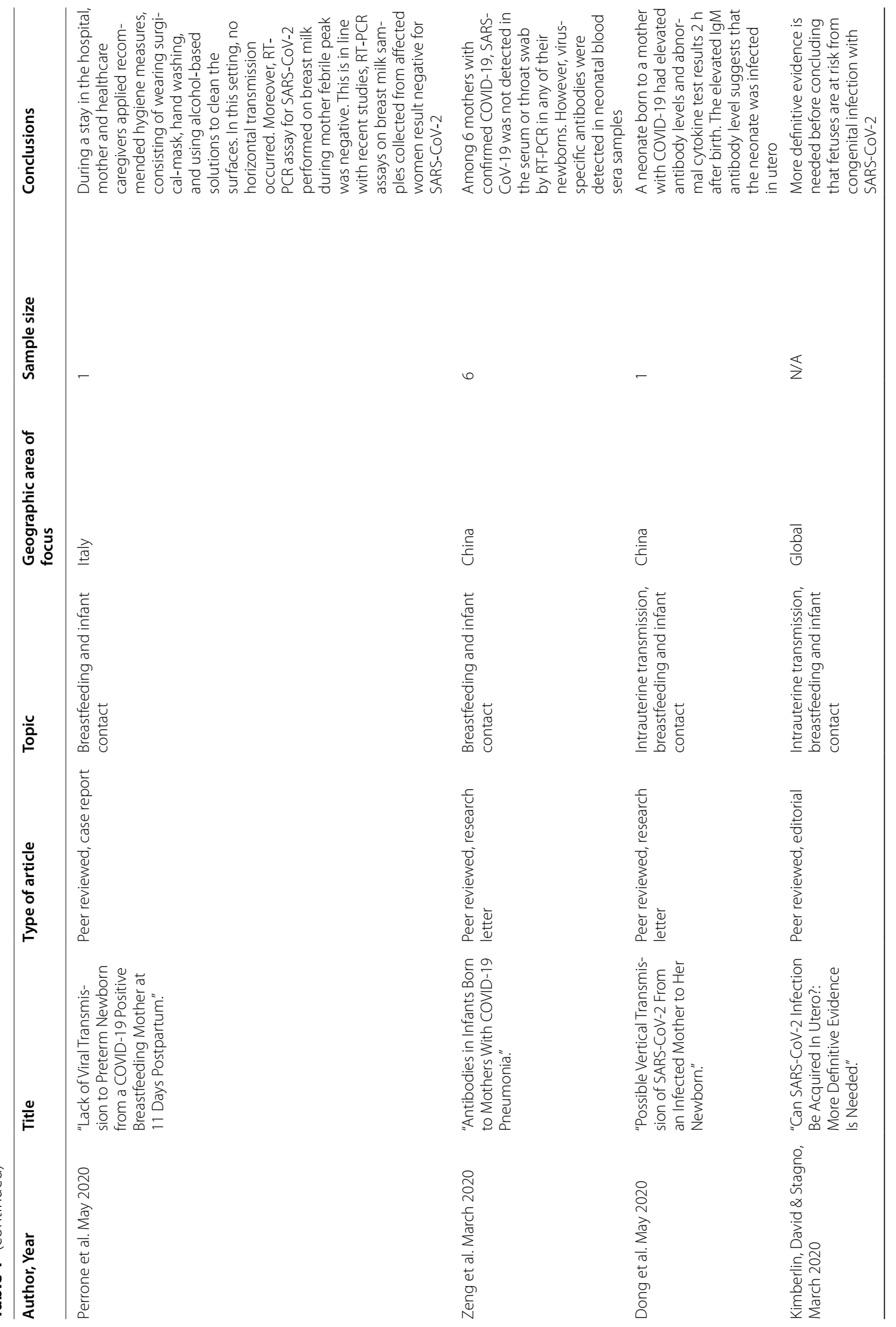




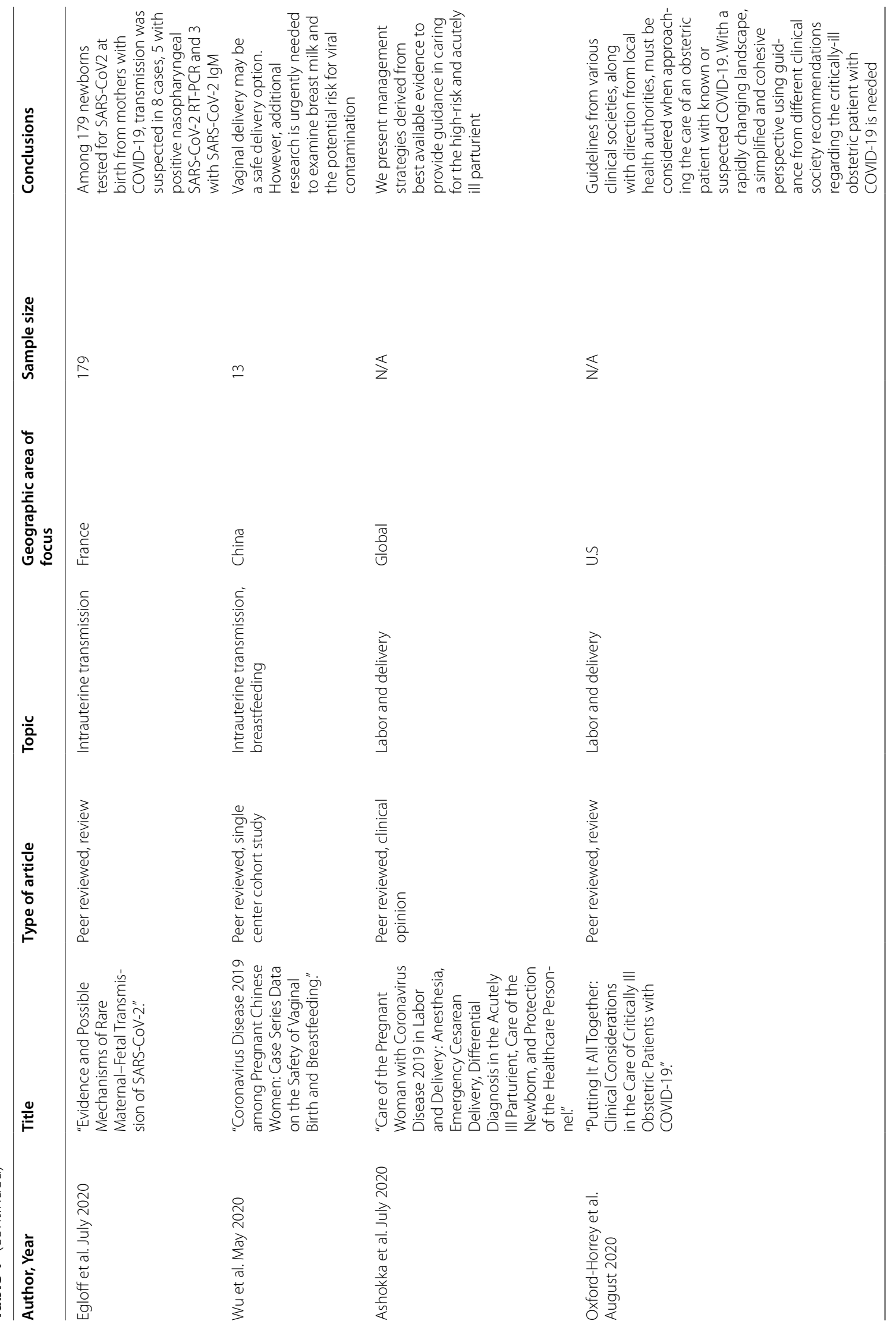




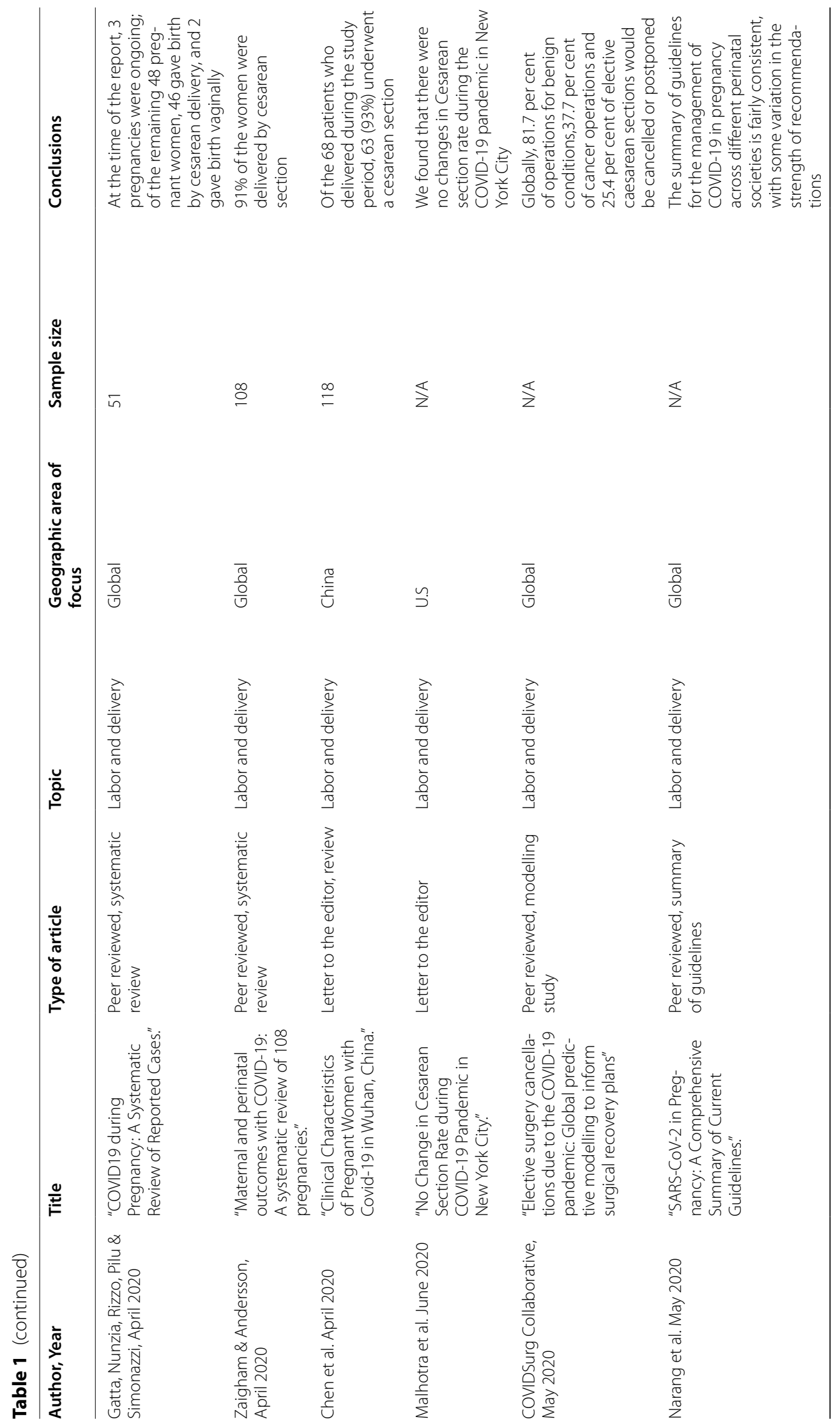




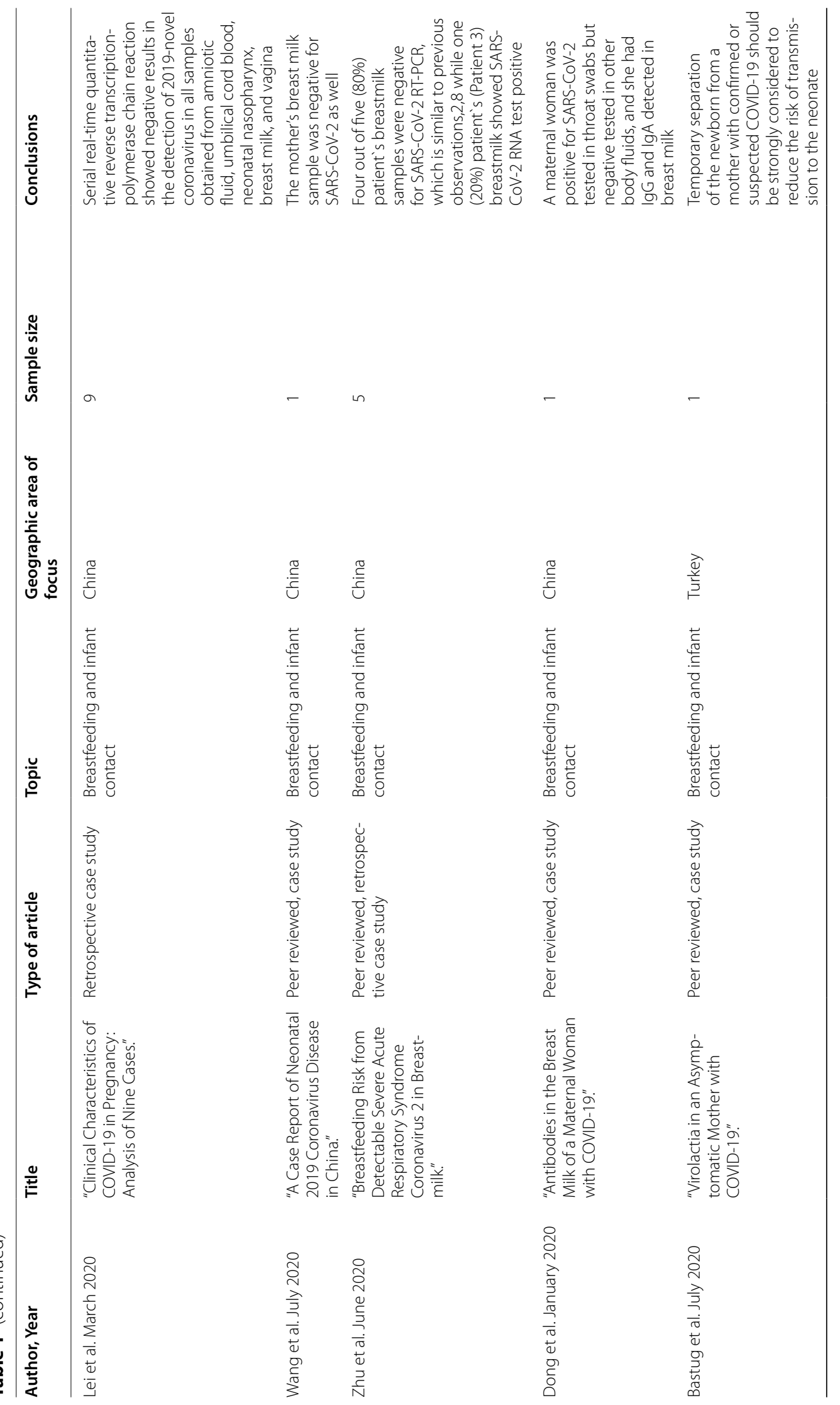




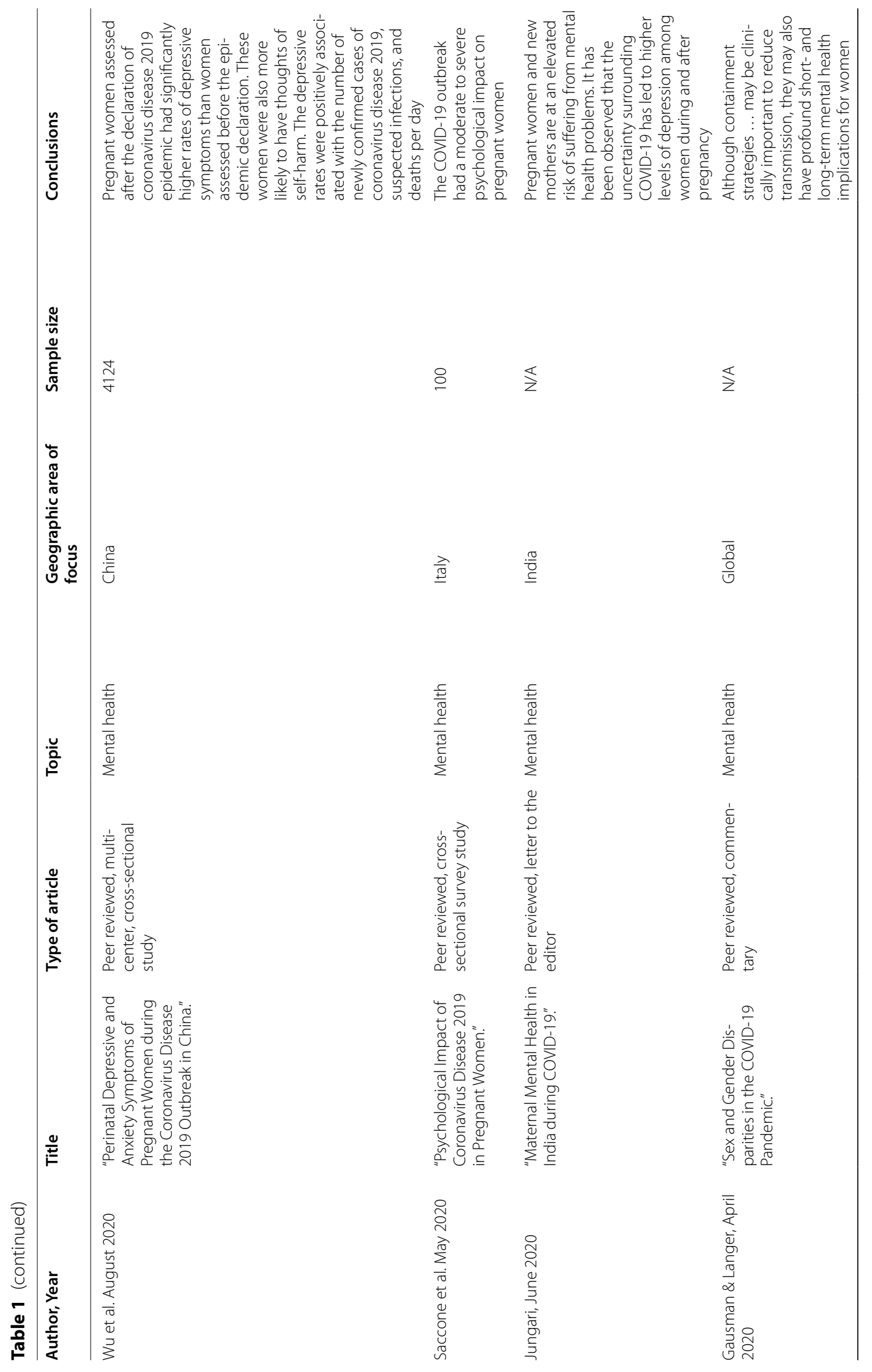




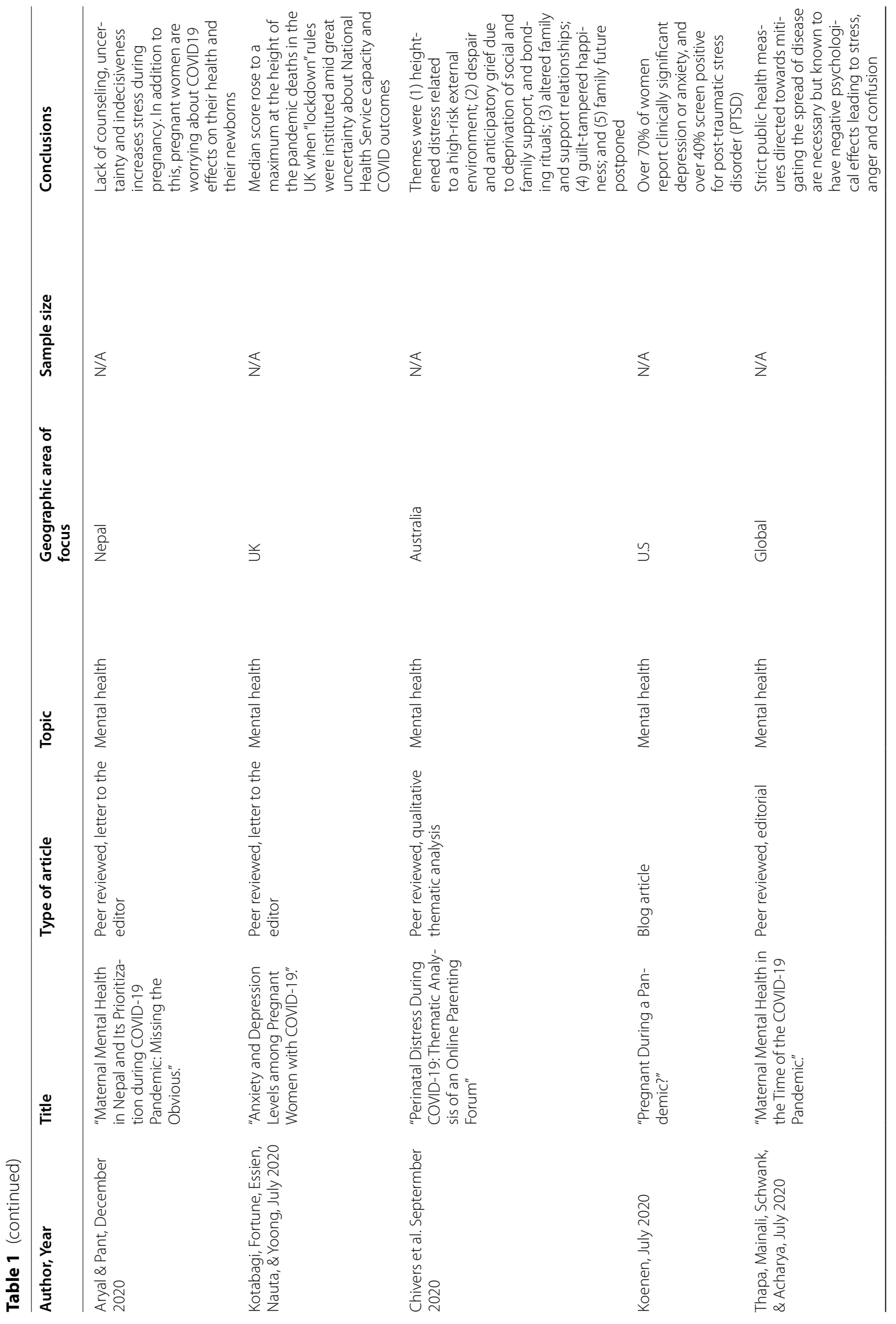




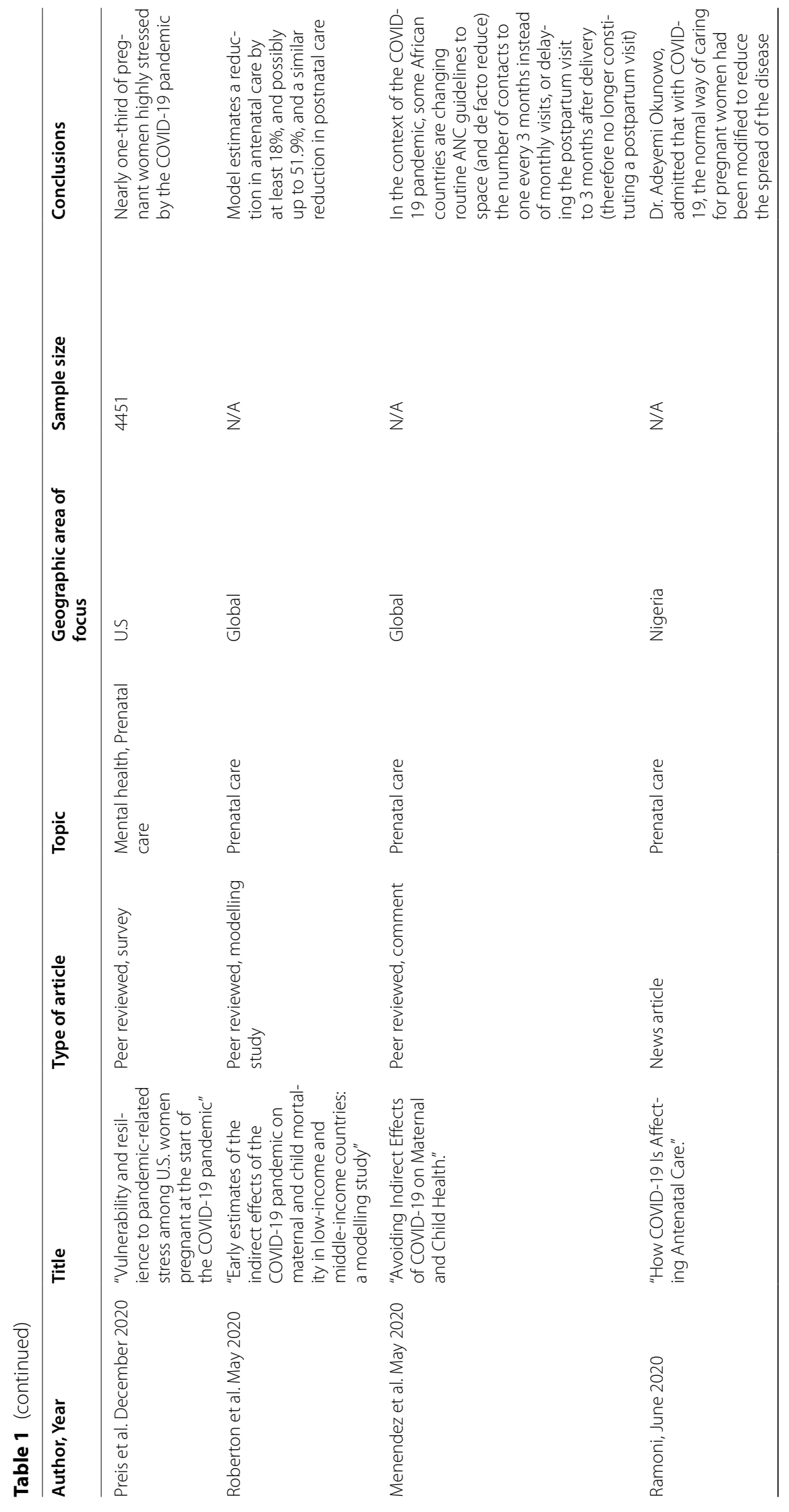




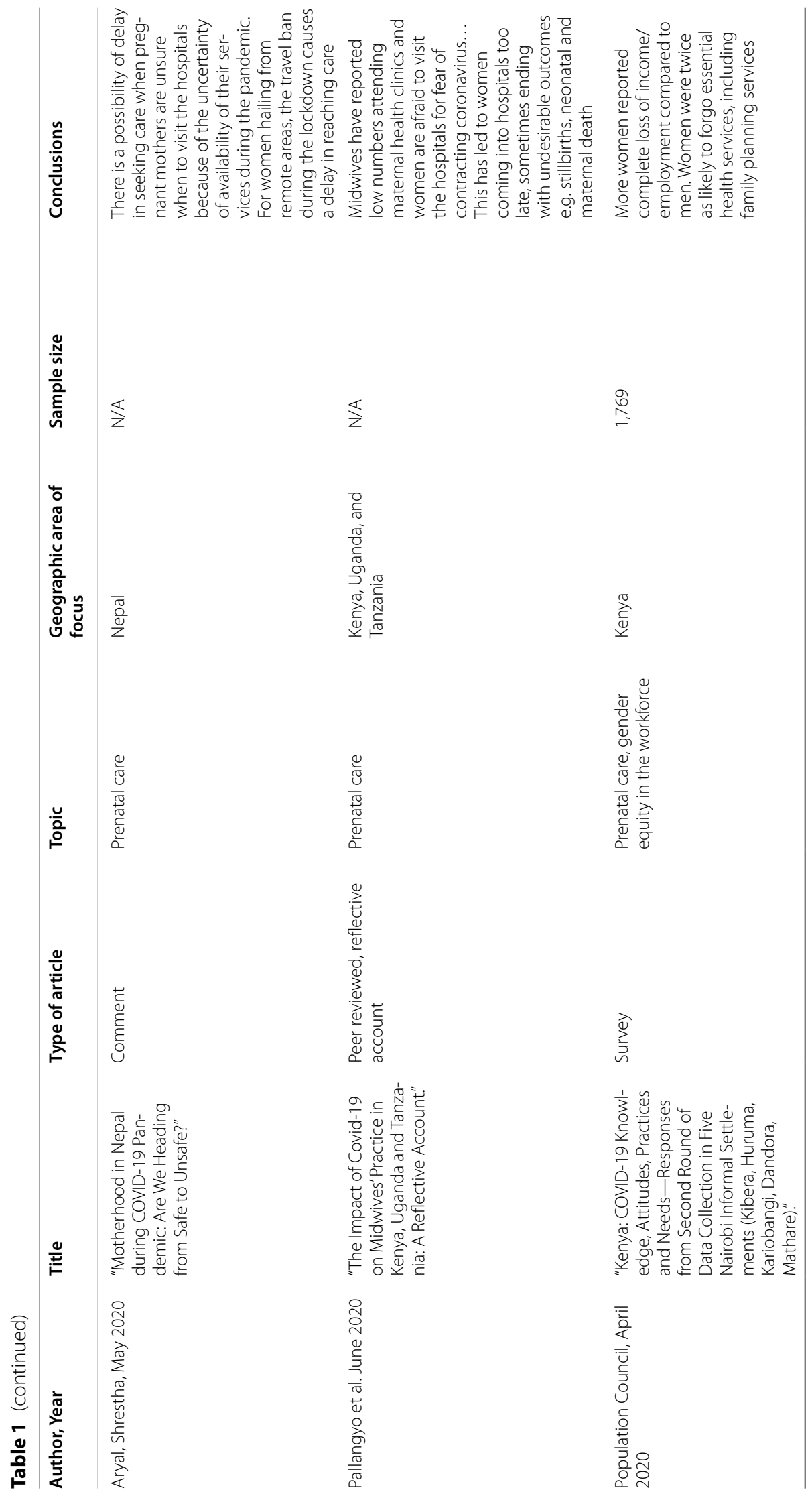




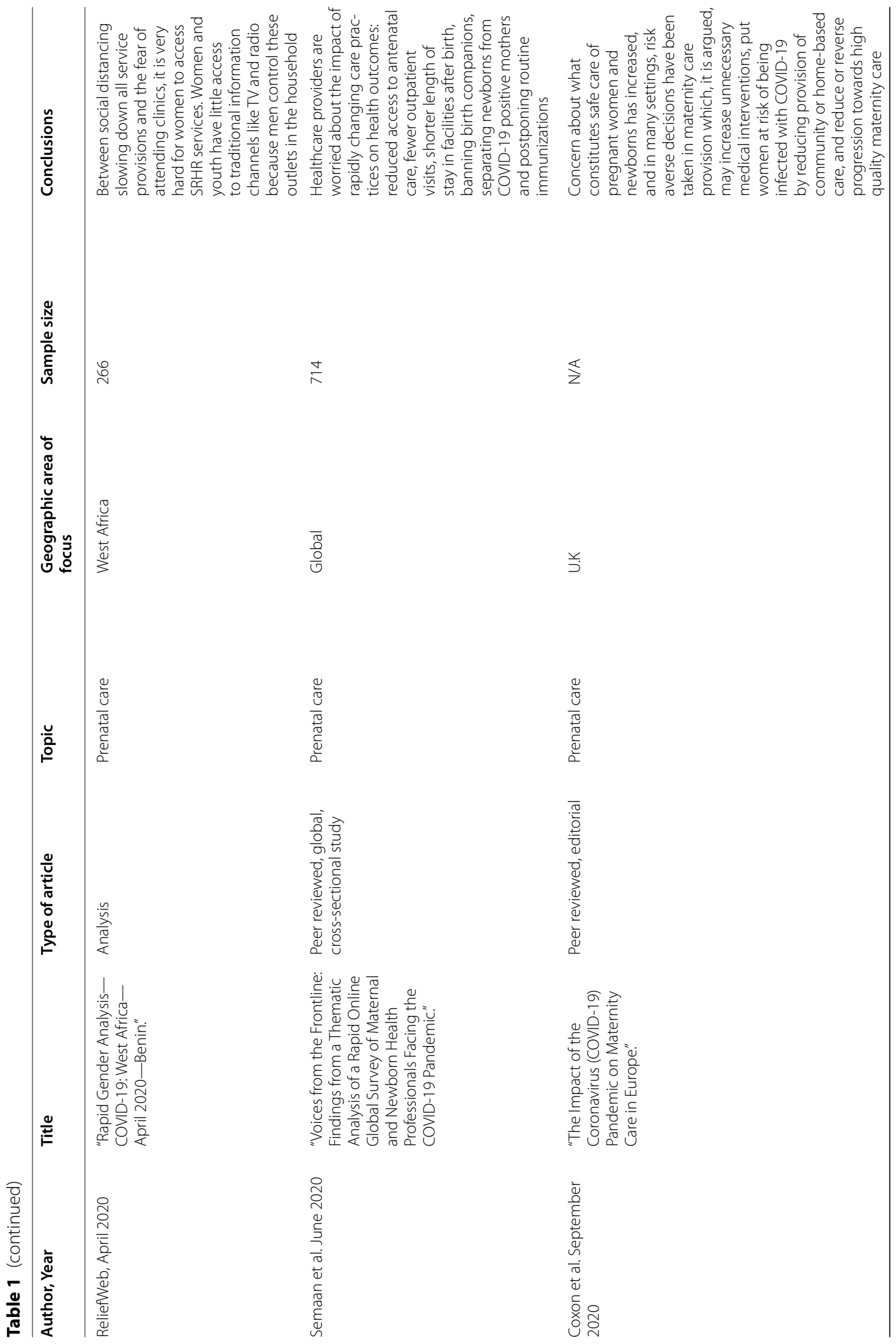




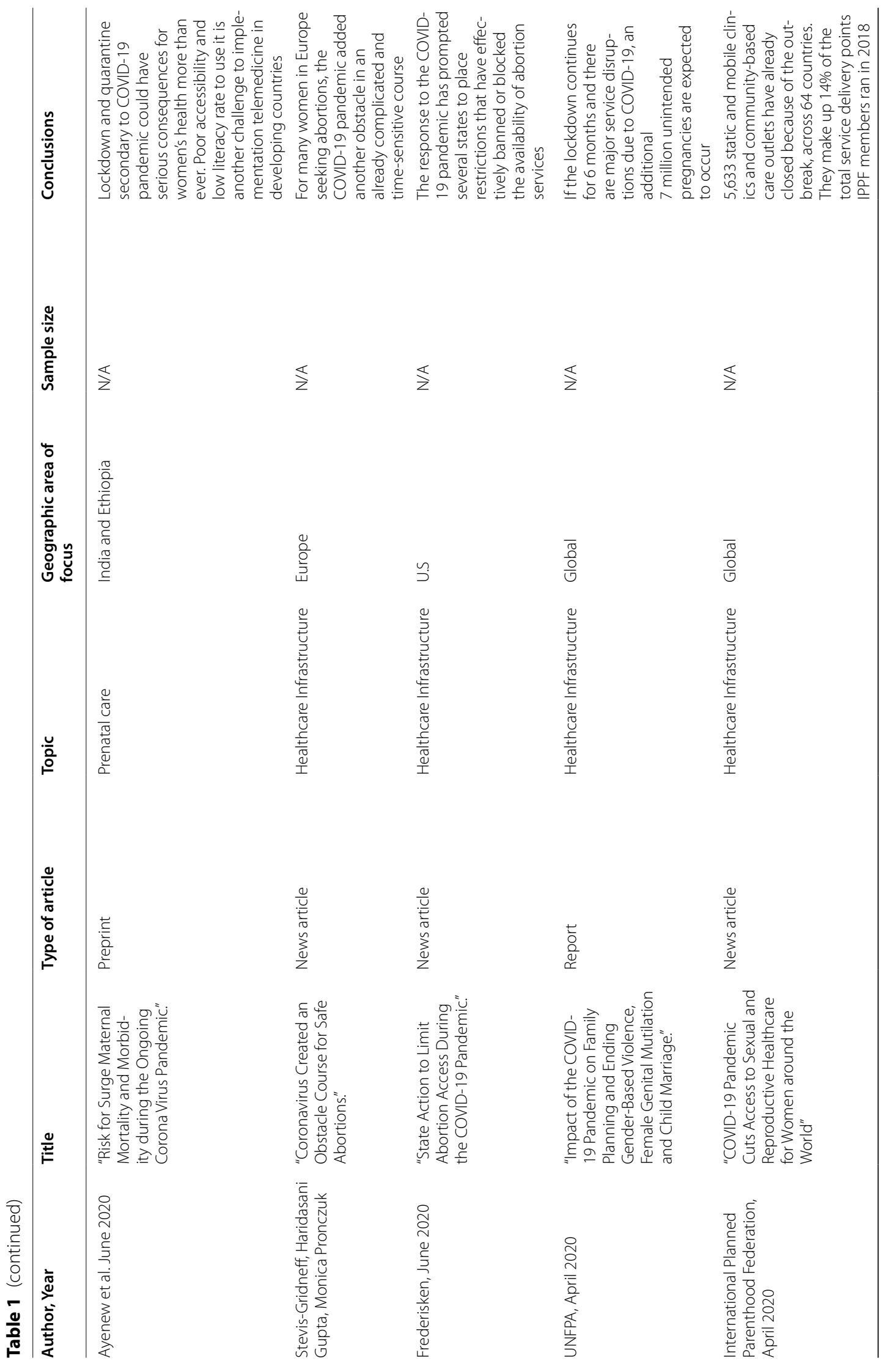




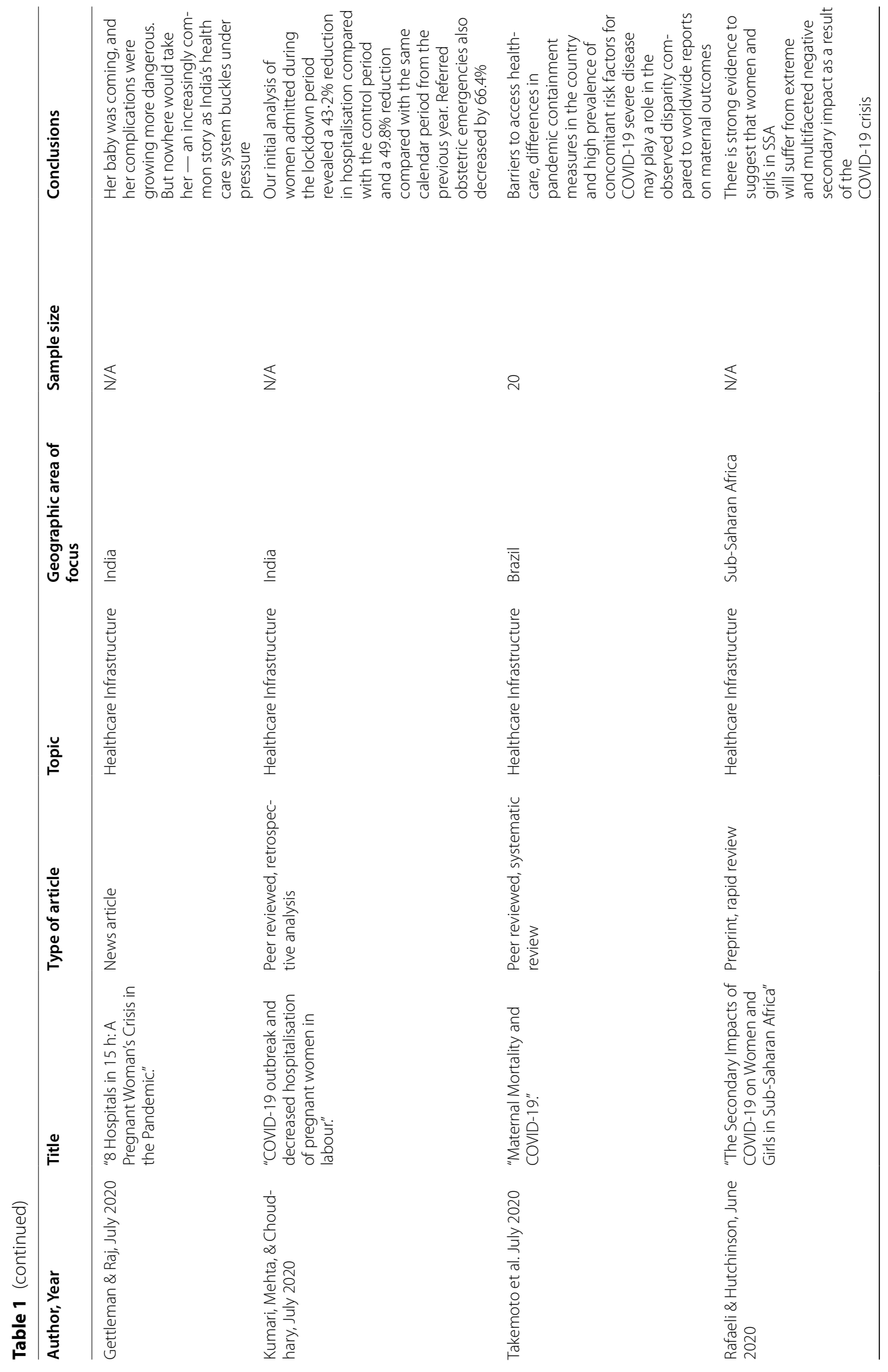




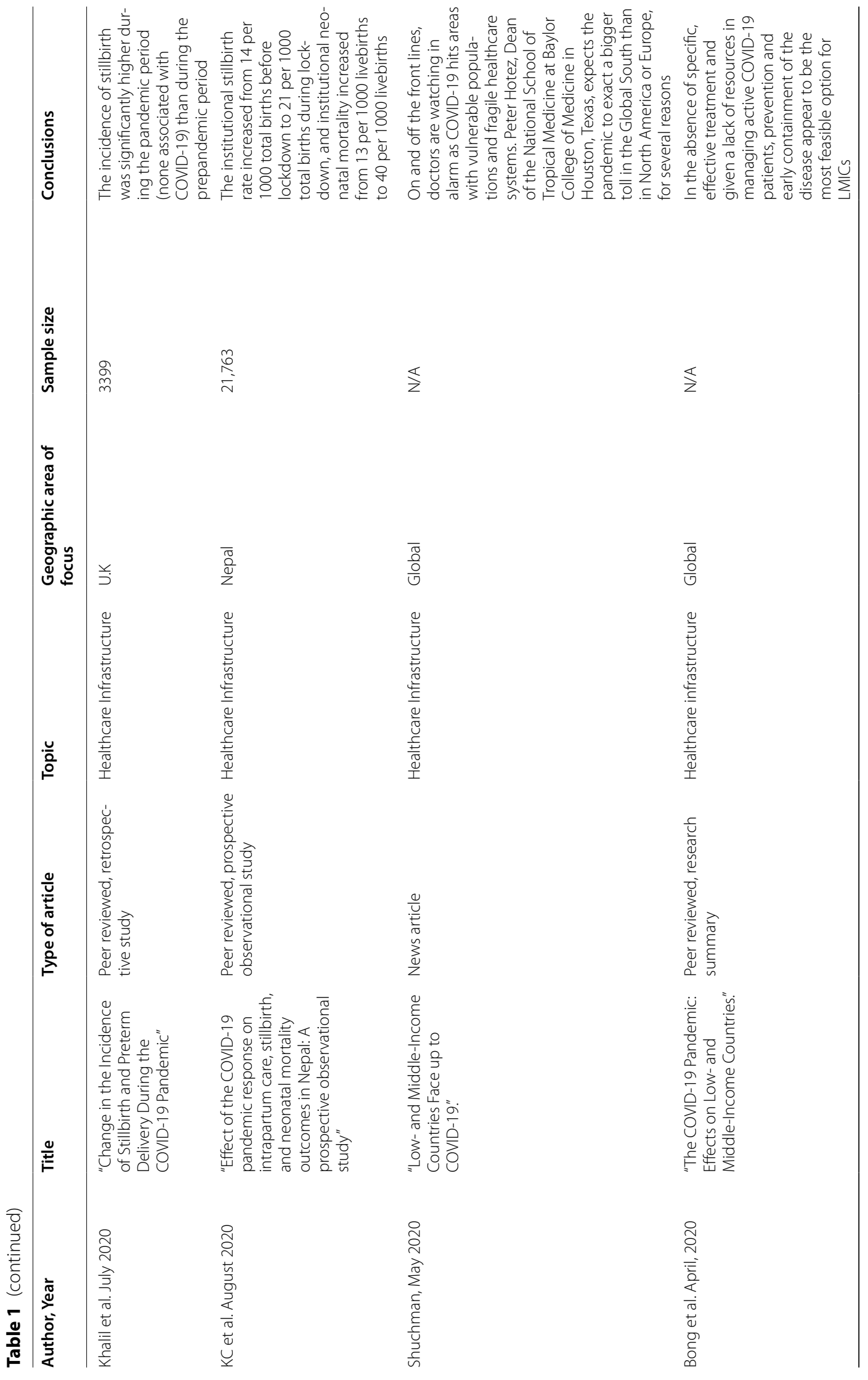




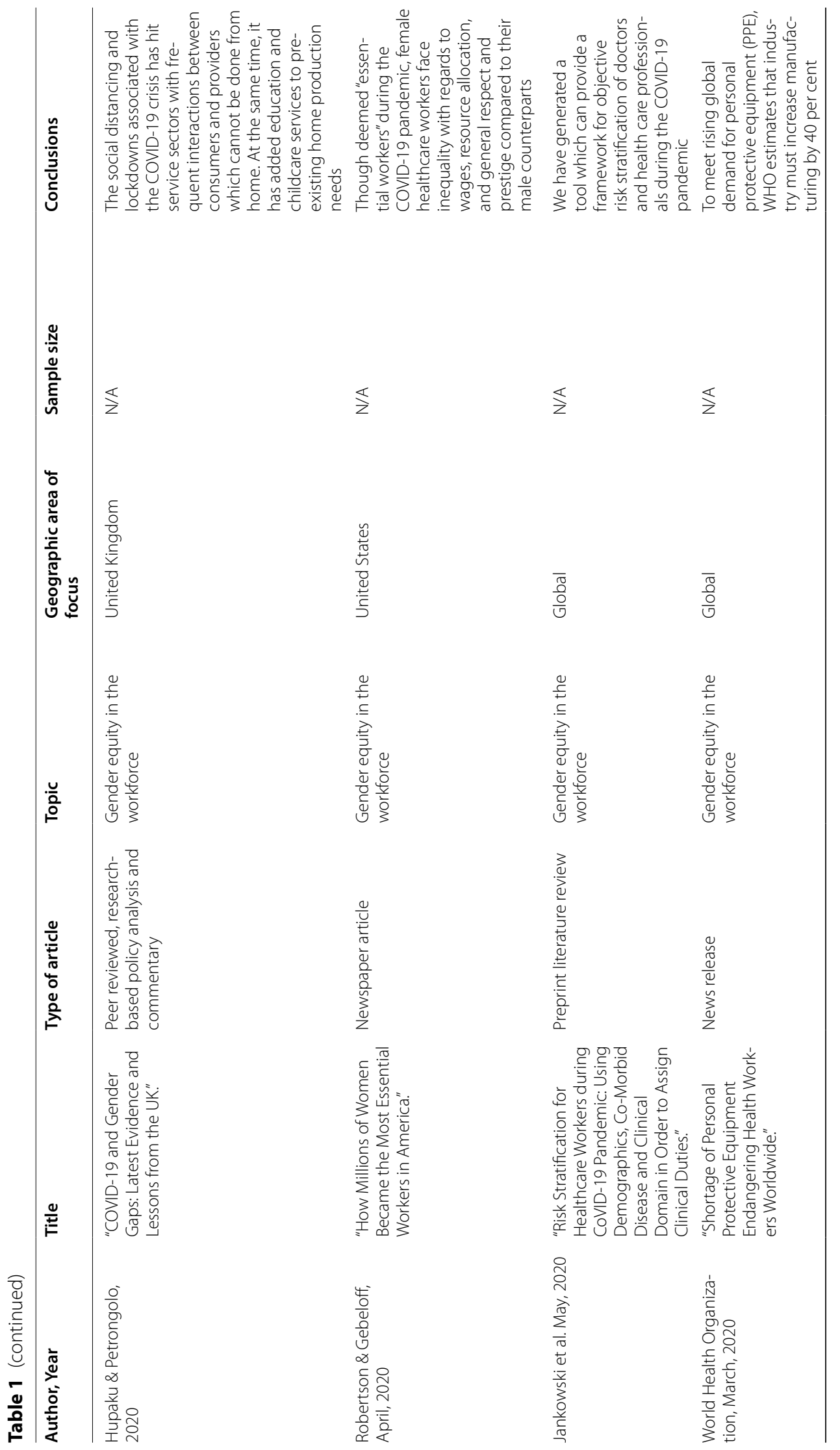




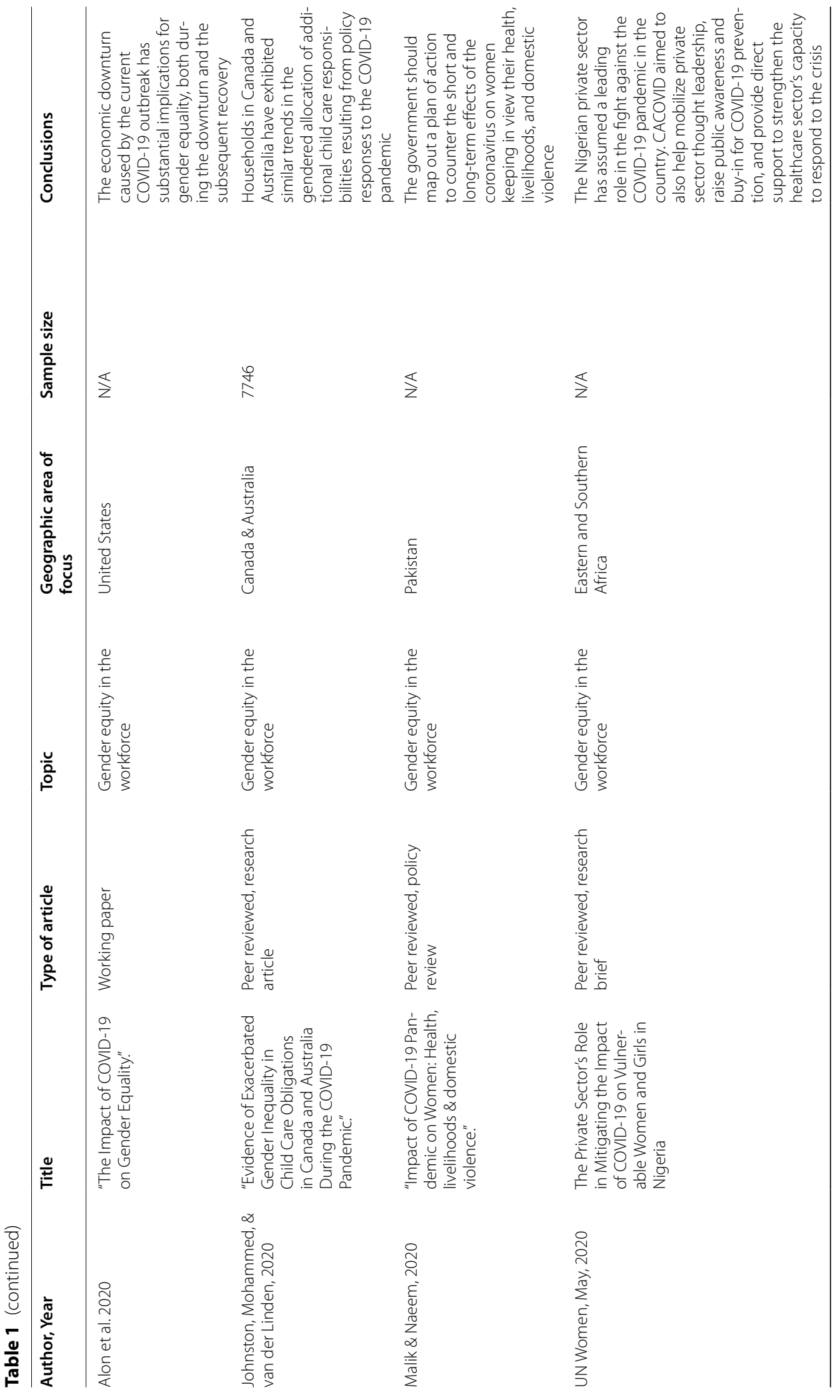




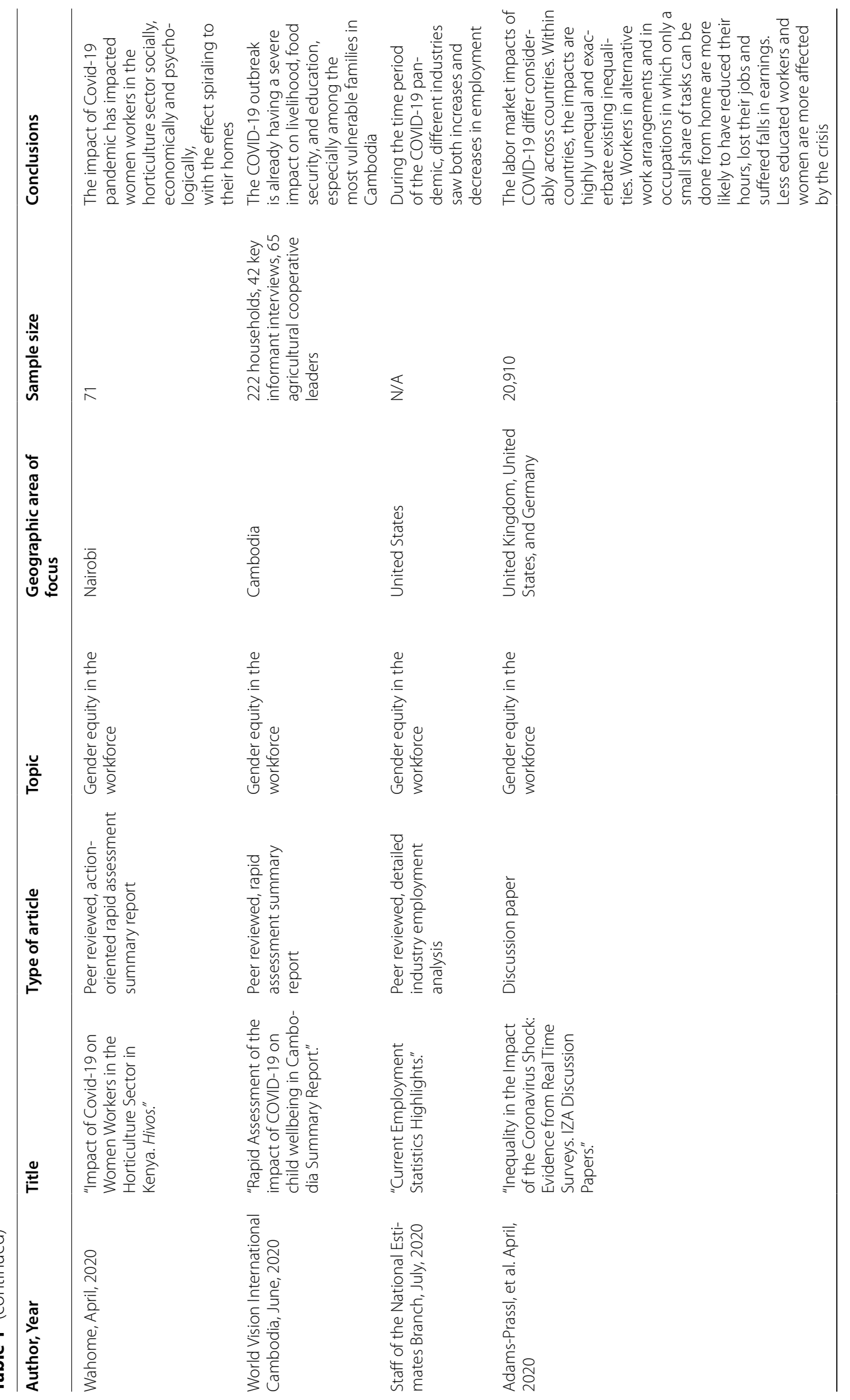




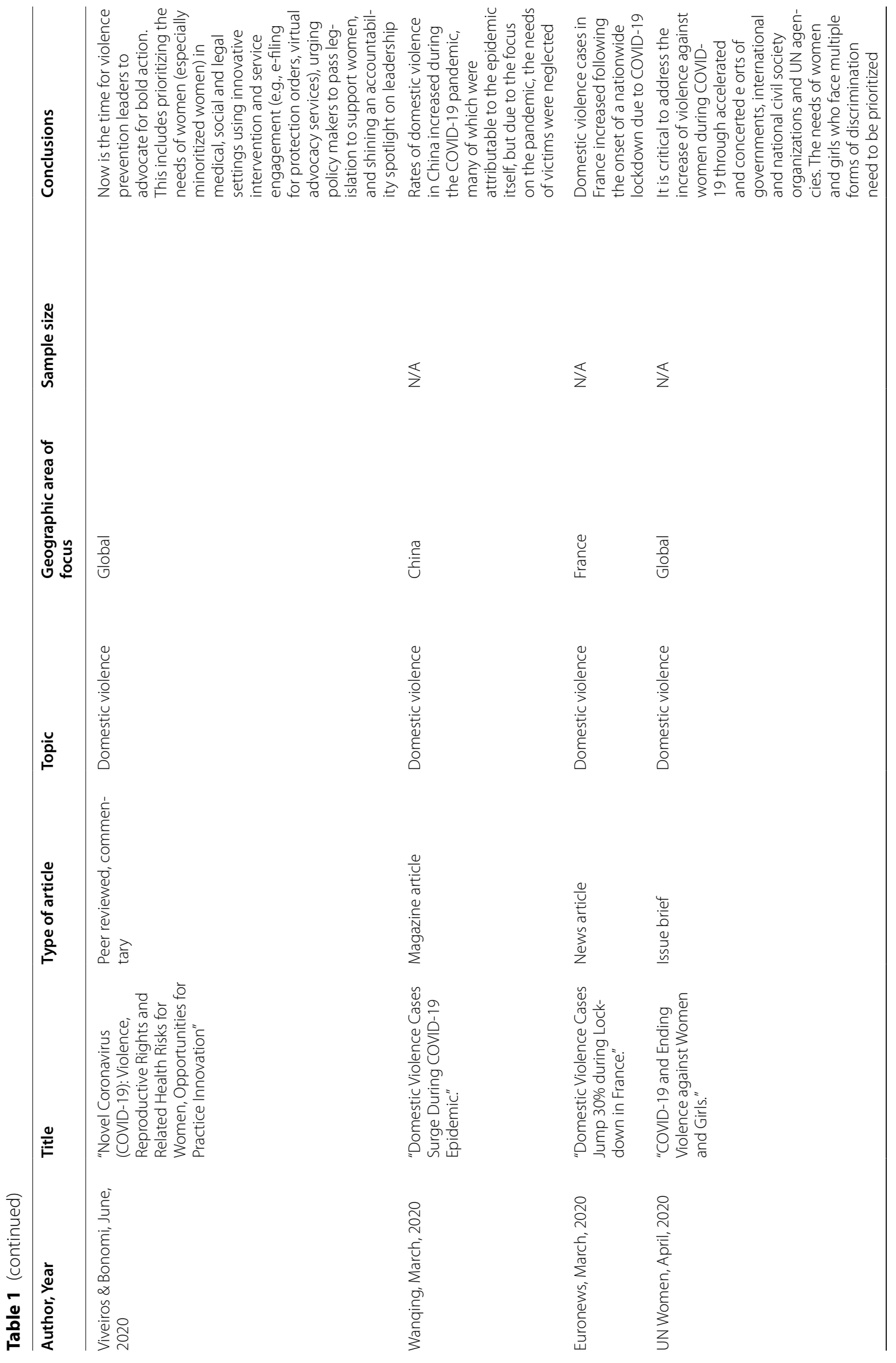




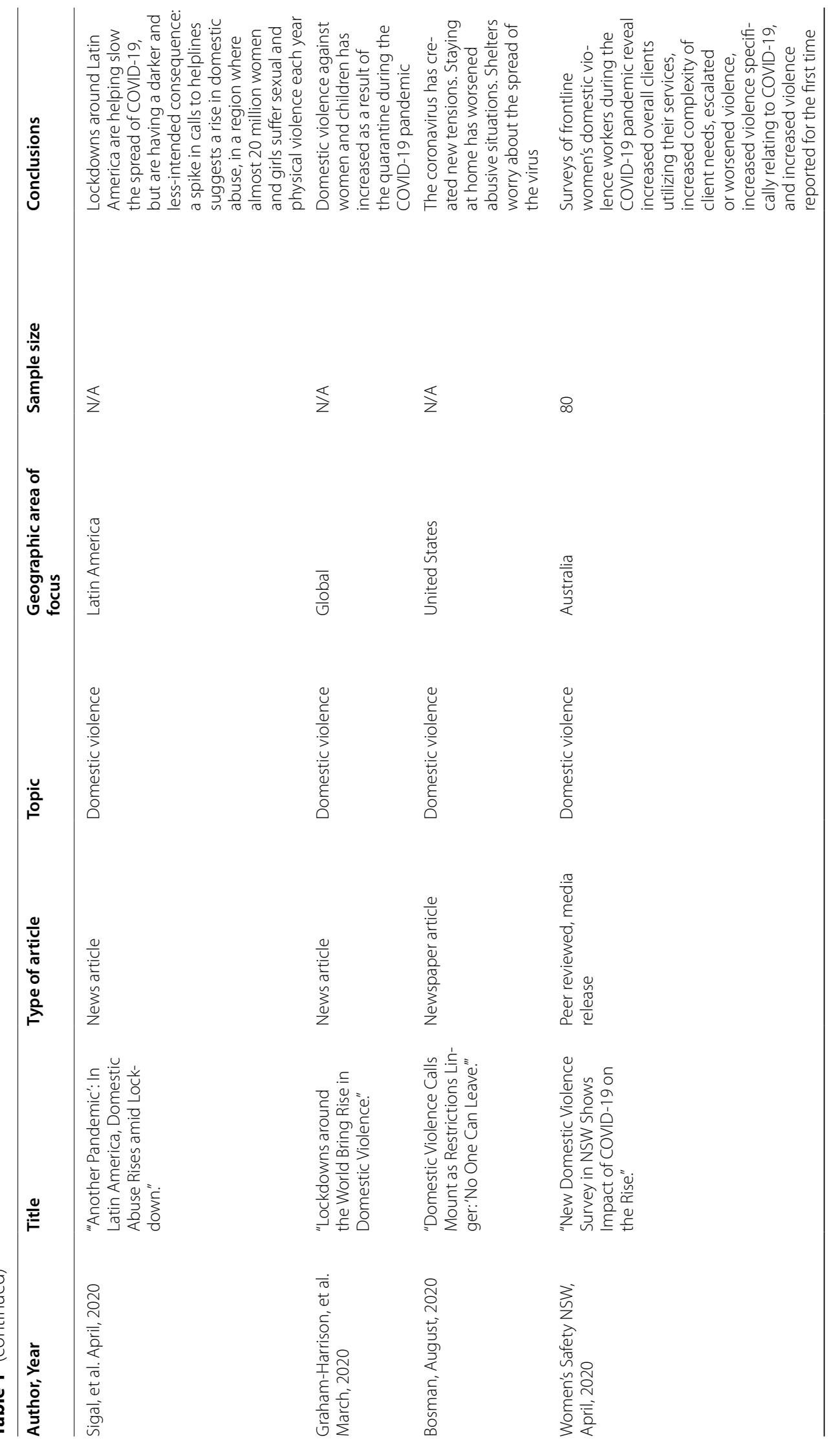




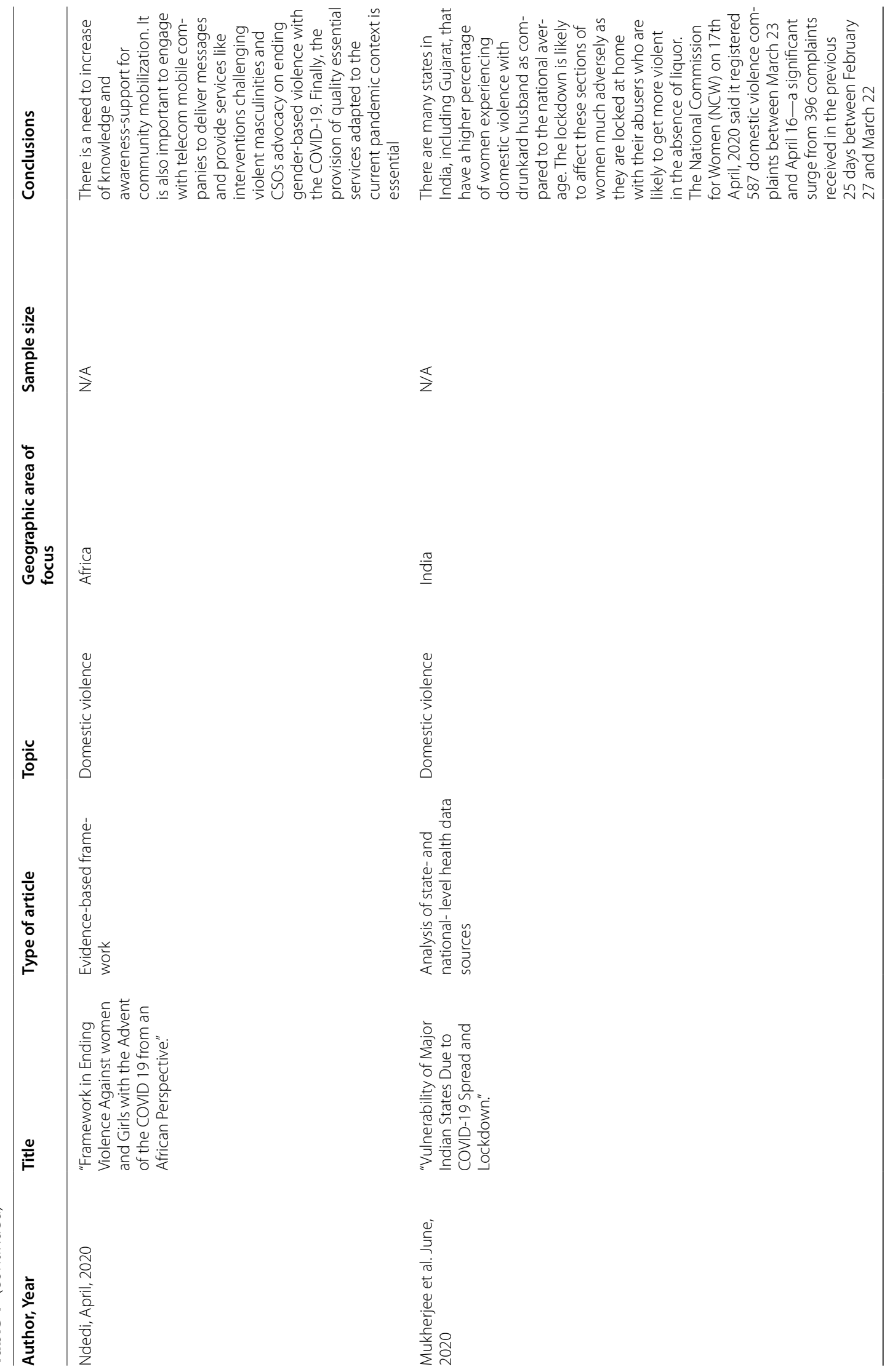




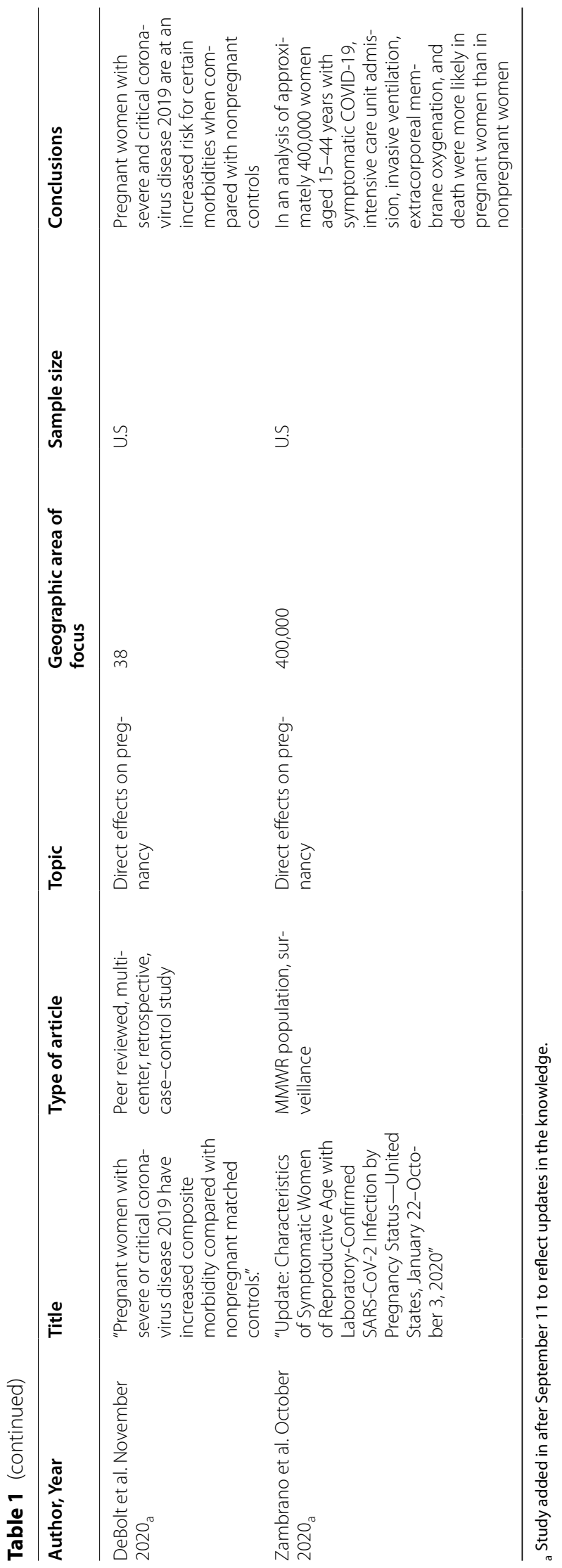


and their children may be at heightened risk for infection with SARS-CoV-2 [2].

In general, pregnant individuals with COVID-19 do not seem to display more severe disease symptoms than nonpregnant individuals. Most cases among pregnant people are asymptomatic or mildly symptomatic [6]. For symptomatic cases, the most common clinical presentations included fever, cough, and dyspnea [7-11]. Laboratory findings consistently included lymphopenia, leukopenia, thrombocytopenia, and elevated levels of $\mathrm{C}$-reactive protein and transaminases [7, 12-14]. Others reported an increased D-dimer level and neutrophil/lymphocyte ratio and a decreased white blood cell count $[8,9]$. Chest computed tomography (CT) scans revealed abnormal imaging features, namely ground-glass opacities, in the lungs of pregnant individuals with COVID-19 [7, 10, 15], but the clinical significance of these imaging findings and the laboratory parameters is not clear.

Adverse outcomes resulting from maternal infection with SARS-CoV-2 during pregnancy are infrequent. In studies from January to September 2020, most cases of COVID-19 among pregnant individuals documented during surveillance in the United States did not progress to severe disease, and intensive care unit (ICU) admission involving mechanical ventilation was seldom required [6]. Results were similar in two studies of pregnant women admitted hospitals in China [7, 16]. However, recently two studies have contradicted these early results. A multicenter, retrospective case control study published in November 2020 compared pregnant women admitted in Philadelphia for severe or critical coronavirus disease to reproductive-aged nonpregnant women admitted for severe or critical coronavirus disease found that pregnant participants were more likely to be admitted to the ICU, to be intubated, to require mechanical ventilation, and were at increased risk of composite morbidity [17]. Similarly, an analysis of 400,000 women in the United States between 15 and 44 years of age with symptomatic COVID-19 published in October 2020 found that pregnant women were more likely to experience ICU admission, intubation, mechanical ventilation, and death [18].

Publications including data from a variety of contexts and designs found that the most commonly reported adverse outcome was preterm delivery [11-13, 19]; and increased prevalence of low birthweight and Cesareansection (C-section) delivery were also observed [10, 20]. Other obstetric complications and outcomes including maternal death, stillbirth, miscarriage, preeclampsia, fetal growth restriction, coagulopathy, and premature rupture of membranes were rare, but apparent [8]. Epidemiological studies did not show that COVID-19 directly increased risks for these outcomes, although a study in London [21] suggests that stillbirths may become more common as a direct or indirect consequence of the pandemic. A prospective cohort study by Mendoza et al. found that pregnant individuals with severe COVID19 may develop a preeclampsia-like syndrome without abnormal ratios of soluble fms-like tyrosine kinase 1 to placental growth factor (sFlt-1/PIGF) and uterine artery pulsatile index (UtAPI) scores typical of normal preeclampsia [22]. Placental infection with the virus was observed; however, these cases were largely asymptomatic or mildly symptomatic [23, 24]. In a review of cases, Golden and Simmons hypothesized that these placental abnormalities were not a direct result of COVID19 infection [25].

\section{Intrauterine transmission}

The literature on maternal-fetal transmission of SARS$\mathrm{CoV}-2$ is highly speculative and requires additional evidence to confirm postulated mechanisms of transmission. Thus far, studies do not support intrauterine infection with COVID-19 resulting from vertical transmission in pregnant individuals with clinically or microbiologically diagnosed cases of the virus during the third trimester [14, 26-28]. Few cases of neonatal infection potentially acquired in utero were observed. For example, samples from six pregnant women with COVID-19 and their neonates in Wuhan, China were tested, and SARSCoV-2 RNA was undetectable in samples of cord blood, throat and nasopharyngeal swabs, urine, feces, amniotic fluid, and placental tissue $[14,29,30]$. Yet, the reliability of these positive neonatal test results was questioned as tests were not performed immediately following delivery. Elevated IgM antibodies in neonates with SARS$\mathrm{CoV}-2$ infection born to SARS-CoV-2-positive mothers were identified at two hospitals in Wuhan, China [31, 32] However, Kimberlin and Stagno raised doubts about intrauterine transmission as IgM antibodies are too large to cross the placenta. Also, IgM assays used to diagnose congenital infection are often unreliable [33]. Low levels of SARS-CoV-2 RNA were found in blood samples collected in two large cohort studies in Wuhan, China $[34,35]$. The occurrence of placental infection with the virus $[23,24]$ and the presence of COVID-19 antibodies in neonatal blood suggest some mechanism of vertical transmission [25].

Despite this, transmission of the virus through blood is questionable. Egloff et al. hypothesized that transcytosis (transcellular transport) of the virus, infected blood cell transport, and virus or infected cells in the cervicovaginal compartment were unlikely avenues for transmission in most pregnant women with COVID-19. According to these data, the maternal-fetal transmission risk is probably very low, possibly under $1 \%$ following maternal SARS-CoV-2 infection during pregnancy [36]. Yet, 
it is widely recognized that further research involving larger population-based longitudinal studies is needed to determine the plausibility of incidental maternal-fetal transmission.

\section{Labor and delivery}

A few case series including an analysis of 108 births occurring in New York City, suggest no increased risk of infection for the neonate when birth occurs vaginally. Despite early reassuring evidence that there is no increased risk of infection for the neonate when birth occurs vaginally [37], clinical guidelines differ in their recommendations on mode of delivery $[38,39]$.

Estimates of C-section rates among women infected with SARS-CoV-2 differed but suggest a potentially significant increase in operative delivery. A systematic review conducted by Della Gatta et al. reported that 90.2\% of women diagnosed with COVID-19 delivered via C-section [40] A systematic review by Zaigham and Andersson reported 91\% of the women delivered via C-section [41] This is similar to early estimates from Wuhan, China; Chen et al. found a C-section occurrence of $93 \%$ [42]. The reasons for this practice are unclear, but it may be attributable to more aggressive management of labor and delivery during the onset of the pandemic. However, a recent analysis of women delivering at New York City hospitals between March 8 and April 2, 2020 found C-section rates not higher than average (31.3\% for women with confirmed COVID-19, compared to $33.9 \%$ of those who tested negative) [43]. Some scientists and healthcare providers speculated that $\mathrm{C}$-section rates are reduced in LMICs due to indirect impacts of the COVID-19 pandemic on the healthcare system [44]. As of the completion of this paper, no evidence to support this exists.

Particularly in the beginning of the pandemic, hospitals implemented policies regarding support persons and postpartum stays that isolated women during labor and delivery. A comprehensive review of care guidelines from international perinatal societies and institutions found that most either recommended no visitors or one asymptomatic support person, and expedited discharge was recommended by the American College of Obstetrics and Gynecology, the Catalan Health Service, and the Society for Maternal and Fetal Medicine [45]. Given the documented benefits of labor support [46], reducing access may increase the incidence of $\mathrm{C}$-section delivery and decrease maternal satisfaction with labor and delivery experiences. Furthermore, expedited discharge may reduce the ability of healthcare providers to identify and treat postpartum complications.

\section{Breastfeeding and infant contact}

The possibility of transmission of novel coronavirus through breast milk is unclear. The published evidence on the presence of SARS-CoV-2 in breastmilk consisted of case reports and case series of postpartum women who tested positive for the coronavirus during pregnancy. Of milk samples collected from 37 women, the majority tested negative for SARS-CoV-2 [26, 32, 39, 47, 48], with the exceptions of $\mathrm{Zhu}$ et al. and Wu et al. who found one positive sample among 5 samples from 5 women [49], and among 3 samples from 3 women, respectively [37]. These preliminary findings suggested that transmission of SARS-CoV-2 through breast milk was unlikely.

Dong et al. reported the presence of IgG and IgA SARSCoV-2 antibodies in breast milk samples taken from a woman with a positive throat swab test for COVID-19 [50]. This suggested that breast milk could have protective effects against infection with COVID-19, though more evidence is needed for confirmation.

Public health and medical organizations released guidance regarding breastfeeding for mothers with confirmed SARS-CoV-2 infection that weighed infection risk with the known and documented benefits of breastfeeding and early bonding. The WHO and UNICEF recommended continued breastfeeding, rooming in, skin to skin contact, and kangaroo care utilizing infection control practices. Specifically, the "WHO recommends that mothers with suspected or confirmed COVID-19 should be encouraged to initiate or continue to breastfeed. Mothers should be counselled that the benefits of breastfeeding substantially outweigh the potential risks for transmission." In contrast, the Centers for Disease Control and Prevention, while encouraging the continuation of breastfeeding in general, stated, "temporary separation of the newborn from a mother with confirmed or suspected COVID-19 should be strongly considered to reduce the risk of transmission to the neonate" [51].

\section{Mental health}

Pregnant women and new mothers are more likely to experience mental illness than non-pregnant individuals [52]. Several COVID-19-related studies in India, China, and Italy of the intrapartum and postpartum periods considered clinically relevant anxiety and depression and their symptoms through self-reports and clinical assessments. Additional maternal mental health issues including substance use disorders and hostility aggression have yet to be studied in depth.

The pandemic significantly impacted maternal mental health. Feelings of anxiety and depression were associated with maternal fear of vertical transmission of the 
virus to their infants, limited accessibility of antenatal care resources, and lack of social support $[53,54]$; these experiences also created a source of stress for pregnant and postpartum women without COVID [27, 55]. Social distancing and isolation/quarantine procedures implemented during the pandemic increased risk of psychological problems among pregnant women and new mothers [53-55].

During pregnancy, self-reported rates of clinically relevant anxiety and depressive symptoms were higher among pregnant women relative to their retrospectively self-assessed pre-pandemic levels and when compared to non-pregnant individuals in a multicenter cross-sectional study performed in China by Y. Wu et al. In the same study, thoughts of self-harm were also more frequent than before the pandemic [52]. Additionally, based on a small case series, Kotabagi et al. proposed a positive correlation between both clinically relevant maternal anxiety and depression and the number of COVID-19-related deaths in the population [56]. The unpredictability of COVID-19, along with deprivation of social and family support, increased perinatal distress [57]. A global survey of pregnant and postpartum women by Koenen and colleagues found that $40 \%$ of women screened positive for post-traumatic stress disorder (PTSD); over $70 \%$ of women also reported clinically significant depression or anxiety [58]. These findings are highly plausible, but must be seen against the background that carefully controlled epidemiological studies are scarce. To establish time trends in psychiatric or trauma prevalence is notoriously difficult as the same population must be assessed with the same measures in the same setting before and during the crises.

The postpartum period was less well-studied than the intrapartum period. Several authors speculated that limited health resources and increased prevalence of home deliveries without trained obstetric clinicians contributed to depression and distress among all pregnant women and new mothers $[53,59]$. Jungari reasoned that heightened levels of clinically relevant depression likely arose from maternal fear of infection for both themselves and their infants, social isolation, and uncertainty surrounding viral spread, but empirical evidence was lacking [54].

\section{Prenatal and postnatal care}

The COVID-19 pandemic required postponement of many non "essential" health services to prevent transmission within clinics, which led to significant reductions in the obtention of antenatal and postnatal care. In the US, an online survey of 4451 pregnant women found nearly a third reported elevated levels of stress, with alterations to prenatal appointments cited as a major reason for this elevation. [60]. A modelling study on the indirect effects of the pandemic in 118 LMIC estimated a reduction in antenatal care by at least $18 \%$, and possibly up to $51.9 \%$, and a similar reduction in postnatal care [61].

This estimate was supported by countries' changes in perinatal care guidelines [62]. A consultant Obstetrician and Gynecologist at the Lagos University Teaching Hospital stated that those in early pregnancy were urged to come in once in eight weeks rather than once in four, and the number of antenatal care visits decreased from 10 to 15 to an average of 6 [63]. Women also chose to forego visits due to lack of transportation, familial pressure to isolate, and personal fears of the virus [64]. Maternal health workers, such as midwives in Kenya, Uganda and Tanzania, reported low numbers attending maternal health clinics, and more women coming into hospitals late, without sufficient antenatal care [65]. A survey by the Population Council sampling heads of households across five Nairobi urban slums found that 9\% of participants forewent health services such as antenatal care and immunization/nutrition services for children [66]. Further, a rapid gender analysis by CARE West Africa found consistent reports of false rumors about the virus and a general mistrust of health workers, leading to some men, especially in rural areas, forbidding their wives from seeking health services. In Mali, most female respondents said they were not accessing health services, out of fear of the virus and confusion about which services were still being offered [67].

A global, cross-sectional study of maternal and newborn health professionals by Semaan et al. found a significant reduction in antenatal care services utilized as clinics reduced hours, number of visitors permitted, and in-person visits during pregnancy [68]. In some areas of the UK, women were provided with blood pressure machines and urinalysis sticks to conduct their own antenatal checks. Some antenatal care was offered via telemedicine, however this varied regionally. Respondents from the UK expressed concerns about the impacts of reduced contact on the quality of maternity care, and participants in LMICs recognized women's inadequate access to communication infrastructure, as telehealth was far more elusive in rural areas, particularly for women $[69,70]$.

\section{Healthcare infrastructure}

The temporary closure of outpatient clinics during shelter at home orders left many women without access to time-sensitive maternal and reproductive health care, from routine gynecological checkups to prenatal care to abortion. Classifying abortion care as "non-essential" severely restricted access regionally or nationwide in many countries during periods of lockdown [71, 72]. The UN Population Fund estimates that if COVID-19 related 
disruption continued for 6 months, 47 million women in 114 LMIC will be unable to use modern contraceptives, and an additional 7 million unintended pregnancies will occur globally [73]. Beyond temporary measures, many clinics closed their doors entirely. By April, 5,633 static and mobile clinics and community-based care outlets closed across 64 countries, according to an International Planned Parenthood Federation survey of its national members [74]. Facilities that remained open were overwhelmed, particularly in LMICs, where many hospitals were already overcrowded. Further, pregnant individuals in many LMICs, with particularly dire numbers in India, were turned away from hospitals or denied ambulances and forced to endure labor on the streets or at home [75, 76]. To mitigate this, hospitals limited the number of people per room and the duration of their stay and reduced postpartum stays. However, this mitigation could negatively impact access to and quality of care.

Semaan et al. revealed that many maternal and newborn healthcare providers worldwide did not receive training in COVID-19 from their health facility, and 53\% of participants in LMICS and 31\% in HICs did not feel knowledgeable in how to care for a COVID-19 maternity patient; $90 \%$ of participants reported higher stress levels [68]. This lack of training and confidence hindered quality of care, with the additional burden of staff and supply shortages. Supply chain breakdowns have left many facilities without access to medications or blood products, which are critical to treating postpartum hemorrhage [70, 73, 74].

While some maternal deaths observed during the pandemic were directly caused by COVID-19, a significant portion may have been attributable to underlying factors. Using evidence from a case series of 20 COVID19-related maternal deaths, Takemoto et al. proposed that inadequacy of the Brazilian healthcare system was responsible for Brazil's high rate of maternal mortality [77]. In Brazil, antenatal care resources were already limited, and even fewer were available during the pandemic as many were repurposed for the care of COVID-19 patients. Likewise, the system failed to address existing public health issues which increased the risk of maternal mortality resulting from COVID-19 among pregnant individuals. Women and girls in Sub-Saharan Africa were also expected to experience significant secondary consequences from the COVID-19 pandemic, leading to a rise in maternal mortality during the pandemic. [78].

Studies in both Nepal and the United Kingdom of pregnant individuals found the incidences of stillbirth and neonatal mortality were significantly higher during the pandemic period than the pre-pandemic period. Those experiencing stillbirth and infant mortality did not show symptoms of COVID-19, suggesting these outcomes may instead be due to the reallocation of medical resources towards COVID-19 patients and the subsequent reduction in hospitalization for labor management and perinatal care visits $[79,80]$. Likewise, another observation is attributed to reduced care: the consistent reductions in preterm birth were seen across various time windows surrounding the implementation of COVID-19 mitigation measures in different countries such as Netherlands, Ireland and Denmark [81] Authors discussed reduced air pollution and maternal stress during pregnancy as potential causal factors; however, a large minority of preterm births, was iatrogenic, suggesting healthcare provider behavior may be a contributing factor. When routine pre-pandemic care was offered, obstetricians may have induced delivery more often due to more close surveillance of pregnancies, usually for maternal or fetal health concerns (e.g. following deviations in cardiotocography). Delivery is more likely to be induced late-preterm, which in the study accounted for all of the prevalence differences [81]. Changes in care-seeking behavior and care availability due to the COVID-19 pandemic may in some contexts lead to potential improved outcomes (reduced preterm delivery), however, this may come with an increase in stillbirth. It is certainly is a major research challenge with potential lessons for obstetric care.

The long-term impacts of the COVID-19 pandemic on maternal health were yet to be determined, but modelling studies indicated potentially grim outcomes particularly for LMICs. Weak healthcare systems in these countries were unable to mount the necessary response to the pandemic, which allowed the virus to spread rapidly [82]. The public health and healthcare sectors in LMICs were chronically under-funded and under-resourced, leaving them ill-prepared to meet the demands of the pandemic and implement the response measures recommended by leading public health organizations [83]. These shortcomings of the healthcare systems in LMICs threatened both the physical and mental health of pregnant and postpartum people.

\section{Gender equity in the workforce}

The social distancing and lockdown measures of the COVID-19 pandemic caused significant consequences for business sectors where interactions between individuals were frequent and often unavoidable. Women were over-represented in these industries; data from the UK Labour Force Survey revealed that approximately $46 \%$ and $39 \%$ of working women and men, respectively, were employed in critical sectors, while $19 \%$ and $13 \%$, respectively, were employed in lockeddown sectors [84]. Safety measures to reduce viral spread revealed that many jobs could be carried out remotely; however, certain essential positions required 
employees to continue to show up in-person and risk exposure. While there was a lack of research on women's role as essential workers, 2019 research by Boniol et al. found that women comprise $70 \%$ of the healthcare workforce worldwide [85]. A New York Times analysis of US census data crossed with the federal government's essential worker guidelines also found that 1 in 3 jobs held by women were designated as essential [86].

While working an essential job provided job security, it also increased the risk of SARS-CoV-2 transmission, particularly in the healthcare workforce, given the high contact nature of medical care, the higher risk individuals who sought it, and the lack of PPE many hospitals faced $[87,88]$. Data show that women tend to bear a larger burden than men of addressing household needs and providing childcare [89]. The burden of domestic work has increased during the Covid-19 pandemic. Approximately nationally representative survey data from Canada and Australia revealed the average Canadian woman with children spent nearly 50 more hours per week on childcare during the pandemic than did the average man, and the average Australian woman with children spent nearly 43 more hours on childcare. Although this disparity in unpaid care work existed prior to the pandemic, childcare needs have increased for many households [90].

In LMICs, the majority of employed women worked in the informal sector, where they did not have access to services such as paid sick leave, maternity leave, or unemployment benefits $[61,91]$. Data from UN Women has found that in Kenya, 60 percent of all job losses recorded since the crisis were held by women [92]. Further, a rapid qualitative assessment by Hivos East Africa found that thousands of females, who are often the main household earners in East Africa, have been laid-off due to the pandemic [93], and surveys by Population Council and World Vision International Cambodia found that a higher percentage of women than men have completely lost their income or earning potential [66, 94].

In several but not all HICs, women were still more likely to become unemployed during the COVID-19 crisis. The U.S. Bureau of Labor Statistics reported that in April 2020 alone, women accounted for $55 \%$ of the 20.5 million jobs lost in America, and that job loss was more prevalent and occurred at a more rapid rate for women than men [95]. A study by Adams-Prassl et al. on large geographically representative samples of individuals in the US, UK, and Germany found that in the UK and US, women faced a higher likelihood than men of losing their jobs or report lower earnings during the pandemic in comparable jobs, even when controlling for job characteristics such as college degree [96]. Conversely, gender did not serve as a significant predictor of job loss in Germany.

\section{Domestic violence}

Lockdown measures required individuals to stay inside for extended periods of time, and early data demonstrated notable spikes in domestic violence (DV). Police data were consulted as evidence of increased violence, and surges in DV cases were noted in several countries [97-101]. In addition, DV hotlines and charities in many countries also experienced higher influxes of calls since January 2020 [97, 98, 100, 102, 103]. Non-representative surveys from Women's Safety New South Wales and Foundation Lance d'Afrique Burundi revealed increased requests for help by survivors to female frontline workers $[104,105]$. The Chief Justice of Kenya announced that in the first two weeks of April alone, gender-based violence cases increased by over a third [78]. Similarly, data from India's National Commission for Women shows that domestic violence complaints more than doubled after Prime Minister Modi announced lockdown on March 24, 2020 [92].

There is a lack of representative epidemiological data on increased DV, and the existing data did not specify if the victims were pregnant or mothers. The breadth of reported cases is alarming, and this increase in DV is expected to be detrimental to maternal health outcomes [105-107]. The actual number of DV incidents is likely higher than reported as lockdown measures and fears of virus spread limited community support for women seeking freedom from abusers $[101,108,109]$.

\section{Discussion}

This study represents a comprehensive scoping review of the direct and indirect impacts of the COVID-19 pandemic on maternal health. By using broad search terms and inclusion criteria, we were able to review literature on social and economic impacts of the pandemic as well as the physical and mental health impacts. However, this study did not include literature in languages other than English, which likely skews results towards countries in which English is the primary language. It was difficult to locate published information on LMICs pertaining to maternal health. We attempted to mitigate this by including grey literature and news articles from a variety of sources. Finally, while a scoping review methodology allowed us to rapidly synthesize literature, it does not represent as rigorous a process as a systematic review or meta-analysis.

While early results suggested otherwise, recent studies with large sample sizes utilizing control groups suggest that pregnant people experiencing symptoms of COVID19 are at higher risk of adverse outcomes than those who are not pregnant $[17,18]$. Additionally, the nonmedical impact of the COVID-19 pandemic is already apparent in this vulnerable population. While short and 
medium-term consequences of these impacts are emerging, the long-term consequences are currently unknown and will require careful research to be elucidated.

To date, studies of the effects of the COVID-19 pandemic have, perhaps understandably, given time constraints and availability of data, lacked rigorous methods. To adequately assess these effects, we require research that carefully controls for pre-COVID-19 levels of the different outcomes of interest (e.g. depressive symptoms, C-Section) and population characteristics (e.g. comorbidity, socio-economic status) to more validly assess time trends. While reducing the frequency of prenatal visits in high income countries (HIC) may not necessarily be associated with worse birth outcomes, reducing the basic antenatal care in low- and middle-income countries (LMIC) is likely to impact maternal and neonatal health $[110,111]$. Continued surveillance and reporting are critical to ascertain whether maternal mortality and morbidity have increased during the pandemic and which populations were affected most severely.

The Covid-19 pandemic has created a multitude of questions regarding the optimal policies to reduce the spread of SARS-Cov-2 while minimizing the unintended detrimental consequences to family wellbeing and gender equity. Salient among these are: in what circumstances should schools and daycares resume care and in what format? Which models of antenatal and delivery care produce optimal outcomes? Which economic relief policies protect gender equity in the workplace and family wellbeing? Heterogeneous and inconsistent application of policies and models for healthcare and childcare delivery both within and across countries, while potentially not ideal for pandemic response, provide a near-natural experiment that helps to explore these questions.

At the same time, policies impacting pregnant and parenting people have been implemented with little evidence. Several of these policies have the potential to significantly harm pregnant individuals' health and undermine their rights. Most concerning are those that limit emotional support during labor and delivery, mandate early infant separation, and shorten postpartum stays. While the clinical rationale behind high C-section rates among pregnant individuals diagnosed with Covid-19 are unclear, these rates are alarming given that no evidence exists that $\mathrm{C}$-section delivery lowers risk of transmission of SARS-CoV-2 or improves maternal health $[81,112]$.

These concerns lead us to provide several clear policy recommendations we believe either have sufficient evidence to merit implementation or must be pursued because of ethical and human rights considerations. The first two pertain to healthcare policy. Given the evidence on the paucity of severe outcomes from SARS-CoV-2 infection in newborns, we urge the CDC to align with the WHO's strong recommendation to keep the mother/ infant dyad together even if the mother has a confirmed infection of SARS-CoV-2. Precautions, of course, are warranted, but our opinion is that the overwhelming evidence behind the benefits of early bonding and breastfeeding outweigh the risk of infection in the newborn.

Second, whenever possible, healthcare organizations should consider the mental health impacts of any policies implemented to reduce risk of transmission. Early and convincing evidence currently exists that maternal mental health issues have increased during the pandemic. Policies that limit or eliminate the ability to give birth with a support person present or that are likely to increase distress, potentially exacerbating underlying mental health issues, should be avoided. With many healthcare organizations shortening postpartum hospital stays or providing postpartum visits through telemedicine, there is also the risk that screening for postpartum depression or other mental health issues will be forgotten or glossed over. Healthcare providers should be vigilant of the increased mental health needs of their pregnant and parenting patients.

Finally, daycare and school closures are causing incredible stress and destabilization to caregivers, especially women, who often bear the brunt of childcare duties. These closures along with other workplace related consequences of the pandemic pose a serious threat to gender equity in the workforce. Without serious mitigation through policy, this threat is potentially far-reaching. We strongly recommend that governments prioritize the resumption of schooling under safe conditions and childcare when easing shelter in place or other pandemicrelated restrictions. Failure to do so is likely to worsen any short-term losses in women's employment given women's disproportionate burden of childcare, and to put vulnerable single-mother and low income households at risk of poverty and food insecurity.

\section{Conclusion}

While rigorous studies have not yet been conducted, early evidence from this scoping review shows that many of the social and economic consequences of the COVID-19 crisis likely affect women more than men. The low risk of mother to child transmission inutero or via breast milk is well documented. It seems that pregnancy may constitute a particularly vulnerable period for COVID-19, but this requires further confirmation through well designed and implemented research. An increased risk of distress and psychiatric problems during pregnancy and postnatally during the pandemic is likely, but also in this case high-quality evidence is lacking. Likewise, a rise in the prevalence of 
domestic violence is plausible and supported by several studies, but we need more representative data. Studies of maternal morbidity and mortality are also lacking. Rigorous epidemiological studies must document the health impact of infection with SARS-CoV-2 during pregnancy as well as the changes in health care service and accessibility and their impact on maternal health. This review, however, provides good evidence that mothers with children are more likely to suffer job and income losses during the pandemic than men and women without children. Single mothers in particular are likely to suffer from food insecurity. These socioeconomic consequences for women are similar across many high- and low-income countries.

$\begin{array}{ll}\text { Abbreviations } & \\ \text { COVID-19 } & \text { Coronavirus Disease 2019 } \\ \text { DV } & \text { Domestic violence } \\ \text { LMIC } & \text { Low- and middle-income countries } \\ \text { HIC } & \text { High income countries } \\ \text { PTSD } & \text { Post-traumatic stress disorder } \\ \text { C-section } & \text { Cesarean section } \\ \text { SARS-CoV-2 } & \text { Severe acute respiratory syndrome coronavirus 2 }\end{array}$

\section{Supplementary Information}

The online version contains supplementary material available at https://doi. org/10.1186/s12978-021-01070-6.

Additional file 1. Pubmed MeSH Terms Utilized for Peer-Reviewed Articles.

\section{Acknowledgements}

None.

\section{Authors' contributions}

BK designed the study, reviewed literature, and drafted the manuscript. EMG and SP retrieved and summarized the literature, reviewed the literature and drafted the manuscript. AL advised on the review and reviewed the final manuscript. HT designed the study, supervised the review process and reviewed the draft and final manuscripts. All authors read and approved the final manuscript.

\section{Funding}

This project was supported by the Health Resources and Services Administration (HRSA) of the U.S. Department of Health and Human Services (HHS) under grant number and title for grant amount (T76 MC000010, Maternal and Child Health Training Grant). This information or content and conclusions are those of the author and should not be construed as the official position or policy of, nor should any endorsements be inferred by HRSA, HHS or the U.S. Government.

\section{Availability of data and materials}

Full review algorithm will be made available.

\section{Ethics approval and consent to participate}

Not applicable in review.

\section{Consent for publication}

Not applicable in review.

\section{Competing interests}

The authors declare that they have no competing interests.

\section{Author details}

${ }^{1}$ Harvard T.H. Chan School of Public Health, Boston, MA, USA. ${ }^{2}$ George Washington University, Washington, DC, USA. ${ }^{3}$ Brown University, Providence, Rhode Island, USA. ${ }^{4}$ Department of Social and Behavioral Science, Harvard T.H. Chan School of Public Health, 677 Huntington Ave., Boston, MA 02115, USA.

Received: 13 October 2020 Accepted: 4 January 2021

Published: 18 January 2021

\section{References}

1. WHO Coronavirus Disease (COVID-19) Dashboard IWHO Coronavirus Disease (COVID-19) Dashboard. (n.d.). Retrieved December 29, 2020, https:// covid19.who.int/table

2. Muralidar S, Ambi SV, Sekaran S, Krishnan UM. The emergence of COVID-19 as a global pandemic: Understanding the epidemiology, immune response and potential therapeutic targets of SARS-CoV-2. Biochimie. 2020;179:85-100. https://doi.org/10.1016/j.biochi.2020.09. 018.

3. Pradhan A, Olsson P-E. Sex differences in severity and mortality from COVID-19: are males more vulnerable? Biol Sex Differ. 2020. https://doi. org/10.1186/s13293-020-00330-7.

4. Arksey H, O'Malley L. Scoping studies: towards a methodological framework. Int J Soc Res Methodol. 2005;8(1):19-32.

5. Braun V, Clarke V. What can "thematic analysis" offer health and wellbeing researchers? Int J Qual Stud Health Well-Being. 2014. https://doi. org/10.3402/qhw.v9.26152.

6. Delahoy MJ. Characteristics and Maternal and Birth Outcomes of Hospitalized Pregnant Women with Laboratory-Confirmed COVID19-COVID-NET, 13 States, March 1-August 22, 2020. Morbidity and Mortality Weekly Report: MMWR; 2020. p. 69.

7. Wu C, Yang W, Wu X, Zhang T, Zhao Y, Ren W, Xia J. Clinical manifestation and laboratory characteristics of SARS-CoV-2 infection in pregnant women. Virologica Sinica. 2020;35(3):305-10. https://doi.org/10.1007/ s12250-020-00227-0.

8. Xu L, Yang Q, Shi H, Lei S, Liu X, Zhu Y, Wu Q, Ding X, Tian Y, Hu Q, Chen $F$, et al. Clinical presentations and outcomes of SARS-CoV-2 infected pneumonia in pregnant women and health status of their neonates. Sci Bull. 2020. https://doi.org/10.1016/j.scib.2020.04.040.

9. Smith V, Seo D, Warty R, Payne O, Salih M, Chin KL, Ofori-Asenso R, et al. Maternal and Neonatal Outcomes Associated with COVID-19 Infection: a Systematic Review. PLoS ONE. 2020;5(6):e0234187. https://doi.org/10. 1371/journal.pone.0234187.

10. Knight M, Bunch K, Vousden N, Morris E, Simpson N, Gale C, O'Brien P, Quigley M, Brocklehurst P, Kurinczuk JJ. Characteristics and Outcomes of Pregnant Women Admitted to Hospital with Confirmed SARSCoV-2 Infection in UK: National Population Based Cohort Study. BMJ. 2020;369:2107. https://doi.org/10.1136/bmj.m2107.

11. Allotey J, Stallings E, Bonet M, Yap M, Chatterjee S, Kew T, Debenham L, Llavall AC, Dixit A, Zhou D, Balaji R, Lee SI, Qiu X, Yuan M, Coomar D, van Wely $M$, van Leeuwen $E$, Kostova E, Kunst $H$. Clinical manifestations, risk factors, and maternal and perinatal outcomes of coronavirus disease 2019 in pregnancy: living systematic review and meta-analysis. BMJ. 2020. https://doi.org/10.1136/bmj.m3320.

12. Pereira A, Cruz-Melguizo S, Adrien M, Fuentes L, Marin E, Perez-Medina T. Clinical Course of Coronavirus Disease-2019 in Pregnancy. Acta Obstetricia et Gynecologica Scandinavica. 2020;99(7):839-47. https:// doi.org/10.1111/aogs.13921.

13. Blitz MJ, Rochelson B, Meirowitz N, Prasannan L, Rafael TJ, et al. Maternal mortality among women with coronavirus disease 2019. Am J Obstetr Gynecol. 2019. https://doi.org/10.1016/j.ajog.2020.06.020.

14. Chen H, Guo J, Wang C, Luo F, Yu X, Zhang W, Li J, Zhao D, Xu D, Gong Q, Liao J, et al. Clinical characteristics and intrauterine vertical transmission potential of COVID-19 infection in nine pregnant women: a retrospective review of medical records. Lancet. 2020;395(10226):809-15. https:// doi.org/10.1016/S0140-6736(20)30360-3.

15. Yang H, Sun G, Tang F, Peng M, Gao Y, Peng J, Xie H, Zhao Y, Jin Z. Clinical features and outcomes of pregnant women suspected of 
coronavirus disease 2019. J Infect. 2020;81(1):e40-44. https://doi.org/10. 1016/j.jinf.2020.04.003.

16. Khan S, Peng L, Siddique R, Nabi G, Xue M, Liu J, Han G. Impact of COVID-19 infection on pregnancy outcomes and the risk of maternalto-neonatal intrapartum transmission of COVID-19 during natural birth. Infect Control Hosp Epidemiol. 2020;41 (6):748-50. https://doi.org/10. 1017/ice.2020.84

17. DeBolt CA, Bianco A, Limaye MA, Silverstein J, Penfield CA, Roman AS, Rosenberg HM, Ferrara L, Lambert C, Khoury R, Bernstein PS. Pregnant women with severe or critical coronavirus disease 2019 have increased composite morbidity compared with nonpregnant matched controls. Am J Obst Gynecol. 2019. https://doi.org/10.1016/j.ajog.2020.11.022.

18. Zambrano LD, Ellington S, Strid P, Galang RR, Oduyebo T, Tong VT, Woodworth KR, Nahabedian III JF, Azziz-Baumgartner E, Gilboa SM, Meaney-Delman D. Update: characteristics of symptomatic women of reproductive age with laboratory-confirmed SARS-CoV- 2 infection by pregnancy status-United States, January 22-October 3, 2020. Morbidity and Mortality Weekly Report. 2020. https://doi.org/10.15585/mmwr. mm6944e3

19. Lokken EM, Walker CL, Delaney S, Kachikis A, Kretzer NM, Erickson A, Resnick R, Vanderhoeven J, Hwang JK, Barnhart N, Rah J. Clinical characteristics of 46 pregnant women with a severe acute respiratory syndrome coronavirus 2 infection in Washington State. Am J Obstet Gynecol. 2020.

20. Savasi VM, Parisi F, Patanè L, Ferrazzi E, Frigerio L, Pellegrino A, Spinillo A, Tateo S, Ottoboni M, Veronese P, Petraglia F. Clinical findings and disease severity in hospitalized pregnant women with coronavirus disease 2019 (COVID-19). Obstetr Gynecol. 2020;136(2):252-8.

21. Khalil A, von Dadelszen P, Draycott T, Ugwumadu A, O'Brien P, Magee L. Change in the Incidence of Stillbirth and Preterm Delivery During the COVID-19 Pandemic. JAMA. 2020:324(7):705-6. https://doi.org/10.1001/ jama.2020.12746.

22. Mendoza M, Garcia-Ruiz I, Maiz N, Rodo C, Garcia-Manau P, Serrano B, Lopez-Martinez RM, Balcells J, Fernandez-Hidalgo N, Carreras E, Suy A. Preeclampsia-like syndrome induced by severe COVID-19: a prospective observational study. BJOG. 2020. https://doi.org/10.1111/14710528.16339.

23. Ferraiolo A, Barra F, Kratochwila C, Paudice M, Vellone VG, Godano E, Varesano S, Noberasco G, Ferrero S, Arioni C. Report of positive placental swabs for SARS-CoV-2 in an asymptomatic pregnant woman with COVID-19. Medicina. 2020;56(6):306.

24. Hosier H, Farhadian S, Morotti R, Deshmukh U, Lu-Culligan A, Campbell K, Yasumoto Y, Vogels C, Casanovas-Massana A, Vijayakumar P, Geng B. SARS-CoV-2 infection of the placenta. medRxiv. 2020.

25. Golden TN, Simmons RA. Maternal and Neonatal Response to COVID19. Am J Physiol Endocrinol Metab. 2020;319(2):E315-9. https://doi.org/ 10.1152/ajpendo.00287.2020.

26. Huntley BJ, Huntley ES, Di Mascio D, Chen T, Berghella V, Chauhan SP. Rates of maternal and perinatal mortality and vertical transmission in pregnancies complicated by severe acute respiratory syndrome coronavirus 2 (SARS-Co-V-2) infection: a systematic review. Obstetr Gynecol. 2020;136(2):303-12.

27. Kotlar B, Gerson E, Petrillo S, Langer A, Tiemeier H. Maternal Transmission of SARS-COV-2 to the Neonate, and Possible Routes for Such Transmission: A Systematic Review and Critical Analysis. BJOG. 2020 https://doi.org/10.1111/1471-0528.16362.

28. Zhang L, Dong L, Ming L, Wei M, Li J, Hu R, Yang J. Severe acute respiratory syndrome coronavirus 2(SARS-CoV-2) infection during late pregnancy: a report of 18 patients from Wuhan China. BMC Pregn Childbirth. 2020;20(1):394. https://doi.org/10.1186/s12884-020-03026-3.

29. Martins-Filho PR, Santos VS, Santos HP. To breastfeed or not to breastfeed? Lack of evidence on the presence of SARS-CoV-2 in breastmilk of pregnant women with COVID-19. Revista Panamericana de Salud Pública. 2020;44: e59. https://doi.org/10.26633/RPSP.2020.59.

30. Perrone S, Giordano M, Meoli A, Deolmi M, Marinelli F, Messina G, Lugani P, Moretti S, Esposito S. Lack of viral transmission to preterm newborn from a COVID-19 positive breastfeeding mother at 11 days postpartum. J Med Virol. 2020. https://doi.org/10.1002/jmv.26037.

31. Zeng H, Xu C, Fan J, Tang Y, Deng Q, Zhang W, Long X. Antibodies in Infants Born to Mothers With COVID-19 Pneumonia. JAMA 2020;323(18):1848-9. https://doi.org/10.1001/jama.2020.4861.
32. Dong L, Tian J, He S, Zhu C, Wang J, Liu C, Yang J. Possible vertical transmission of SARS-CoV-2 from an infected mother to her newborn. JAMA. 2020;323(18):1846-8. https://doi.org/10.1001/jama.2020.4621.

33. Kimberlin DW, Stagno S. Can SARS-CoV-2 infection be acquired in utero?: more definitive evidence is needed. JAMA. 2020;323(18):1788-9. https://doi.org/10.1001/jama.2020.4868.

34. Huang C, Wang Y, Li X, Ren L, Zhao J, Hu Y, Zhang L, Fan G, Xu J, Gu X, Cheng Z. Clinical Features of Patients Infected with 2019 Novel Coronavirus in Wuhan China. Lancet. 2020:395(10223):497-506.

35. Wang W, Yanli X, Gao R, Roujian L, Han K, Guizhen W, Tan W. Detection of SARS-CoV-2 in different types of clinical specimens. JAMA. 2020;323(18):1843-4. https://doi.org/10.1001/jama.2020.3786.

36. Egloff C, Vauloup-Fellous C, Picone O, Mandelbrot L, Roques P. Evidence and possible mechanisms of rare maternal-fetal transmission of SARSCoV-2. J Clin Virol. 2020;128:104447. https://doi.org/10.1016/j.jcv.2020. 104447.

37. Wu Y, Liu C, Dong L, Zhang C, Chen Y, Liu J, Zhang C, et al. Coronavirus Disease 2019 among pregnant chinese women: case series data on the safety of vaginal birth and breastfeeding. BJOG. 2020;127(9):1109-15. https://doi.org/10.1111/1471-0528.16276.

38. Ashokka B, Loh MH, Tan CH, Su LL, Young BE, Lye DC, Biswas A, Illanes $\mathrm{SE}$, Choolani M. Care of the pregnant woman with coronavirus disease 2019 in labor and delivery: anesthesia, emergency cesarean delivery, differential diagnosis in the acutely ill parturient, care of the newborn, and protection of the healthcare personnel. Am J Obstetr Gynecol. 2020;223:66-74. https://doi.org/10.1016/j.ajog.2020.04.005.

39. Oxford-Horrey C, Savage M, Prabhu M, Abramovitz S, Griffin K, LaFond E, Riley L, Easter SR. Putting it all together: clinical considerations in the care of critically ill obstetric patients with COVID-19. Am J Perinatol. 2020;37(10):1044-51. https://doi.org/10.1055/s-0040-1713121.

40. Della Gatta AN, Rizzo R, Pilu G, Simonazzi G. COVID19 during pregnancy: a systematic review of reported cases. Am J Obst Gynecol. 2020.

41. Zaigham M, Andersson O. Maternal and perinatal outcomes with COVID-19: a systematic review of 108 pregnancies. Acta Obstet Gynecol Scand. 2020;99(7):823-9. https://doi.org/10.1111/aogs.13867.

42. Chen L, Li Q, Zheng D, Jiang H, Wei Y, Zou L, Feng L, Xiong G, Sun G, Wang $H$, Zhao $Y$. Clinical characteristics of pregnant women with Covid19 in Wuhan, China. N Engl J Med. 2020.

43. Malhotra Y, Miller R, Bajaj K, Sloma A, Wieland D. No Change in Cesarean Section Rate during COVID-19 Pandemic in New York City. Eur J Obst Gynecol Reprod Biol. 2020. https://doi.org/10.1016/j.ejogrb.2020.06.010.

44. COVIDSurg Collaborative. Elective surgery cancellations due to the COVID-19 pandemic: Global predictive modelling to inform surgical recovery plans. Br J Surg. 2020. https://doi.org/10.1002/bjs.11746.

45. Narang K, Ibirogba ER, Elrefaei A, Trad AT, Theiler R, Nomura R, Picone O, Kilby M, Escuriet R, Suy A, Carreras E. SARS-CoV-2 in pregnancy: a comprehensive summary of current guidelines. J Clin Med. 2020;9(5):1521. https://doi.org/10.3390/jcm9051521.

46. Continuous support for women during childbirth—Bohren, MA - 2017 Cochrane Library. (n.d.). Retrieved December 29, 2020, from https://doi. org/10.1002/14651858.CD003766.pub6/full?cookiesEnabled.

47. Lei D, Wang C, Li C, Fang C, Yang W, Chen B, Wei M, Xu X, Yang H, Wang S, Fan C. Clinical characteristics of COVID-19 in pregnancy: analysis of nine cases. Chin J Perinatal Med. 2020 Mar 16;23(3):225-31.

48. Wang S, Guo L, Chen L, Liu W, Cao Y, Zhang J, Feng L. A case report of neonatal 2019 coronavirus disease in China. Clin Infect Dis. 2020;71(15):853-7. https://doi.org/10.1093/cid/ciaa225.

49. Zhu C, Liu W, Su H, Li S, Shereen MA, Lv Z, Niu Z, Li D, Liu F, Luo Z, Xia Y. nBreastfeeding risk from detectable severe acute respiratory syndrome coronavirus 2 in Breastmilk. J Infect. 2020. https://doi.org/10.1016/j.jinf. 2020.06.001.

50. Dong Y, Chi X, Hai H, Sun L, Zhang M, Xie WF, Chen W. Antibodies in the breast milk of a maternal woman with COVID-19. Emerg Microbes Infect. 2020;9(1):1467-9. https://doi.org/10.1080/22221751.2020.17809 52.

51. Bastug A, Hanifehnezhad A, Tayman C, Ozkul A, Ozbay O, Kazancioglu S, Bodur H. Virolactia in an asymptomatic Mother with COVID-19. Breastfeeding Med. 2020;15(8):488-91. https://doi.org/10.1089/bfm.2020. 0161.

52. Wu Y, Zhang C, Liu H, Duan C, Li C, Fan J, Li H, Chen L, Xu H, Li X, Guo Y. Perinatal depressive and anxiety symptoms of pregnant women during 
the coronavirus disease 2019 outbreak in China. Am J Obstetr Gynecol. 2020;223(2):240. https://doi.org/10.1016/j.ajog.2020.05.009.

53. Saccone G, Florio A, Aiello F, Venturella R, De Angelis MC, Locci M, Bifulco G, Zullo F, Sardo AD. Psychological impact of coronavirus disease 2019 in pregnant women. Am J Obstetr Gynecol. 2019. https://doi.org/ 10.1016/j.ajog.2020.05.003.

54. Jungari S. Maternal Mental Health in India during COVID-19. Public Health. 2020;185:97-8. https://doi.org/10.1016/j.puhe.2020.05.062.

55. Aryal S, Pant SB. Maternal mental health in Nepal and its prioritization during COVID-19 pandemic: missing the obvious. Asian J Psychiatry. 2020;54:102281. https://doi.org/10.1016/j.ajp.2020.102281.

56. Kotabagi P, Fortune L, Essien S, Nauta M, Yoong W. Anxiety and depression levels among pregnant women with COVID-19. Acta Obstetricia et Gynecologica Scandinavica. 2020;99(7):953-4. https://doi.org/10.1111/ aogs.13928.

57. Chivers BR, Garad RM, Boyle JA, Skouteris H, Teede HJ, Harrison CL. Perinatal distress During COVID-19: thematic analysis of an online parenting forum. J Med Internet Res. 2020;22(9):e22002. https://doi.org/ 10.2196/22002.

58. Koenen KC. Pregnant During a Pandemic? Psychology Today. 2020. https://www.psychologytoday.com/us/blog/mental-health-aroundthe-world/202007/pregnant-during-pandemic?eml

59. Thapa SB, Mainali A, Schwank SE, Acharya G. Maternal Mental Health in the Time of the COVID-19 Pandemic. Acta Obstetricia et Gynecologica Scandinavica. 2020;99(7):817-8. https://doi.org/10.1111/aogs.13894.

60. Thomas C, Morris SM, Clark D. Place of death: preferences among cancer patients and their carers. Soc Sci Med. 2004;58(12):2431-44. https:// doi.org/10.1016/j.socscimed.2020.113348.

61. Early estimates of the indirect effects of the COVID-19 pandemic on maternal and child mortality in low-income and middle-income countries: a modelling study. 2020. https://www.thelancet.com/pdfs/journ als/langlo/PIIS2214-109X(20)30229-1.pdf

62. Menendez C, Gonzalez R, Donnay F, Leke RG. Avoiding indirect effects of COVID-19 on maternal and child health. Lancet Global Health. 2020.

63. Ramoni R. How COVID-19 Is Affecting Antenatal Care. Daily Trust. 2020, sec. News. https://dailytrust.com/how-covid-19-is-affecting-anten atal-care.

64. Aryal S, Shrestha D. Motherhood in Nepal during COVID-19 pandemic: are we heading from safe to unsafe?. J Lumbini Med College. 2020. https://doi.org/10.22502/jlmc.v8i1.351.

65. Pallangyo E, Nakate MG, Maina R, Fleming V. The impact of Covid-19 on midwives' practice in Kenya, Uganda and Tanzania: a reflective account. Midwifery. 2020. https://doi.org/10.1016/j.midw.2020.102775.

66. Population Council. Kenya: COVID-19 Knowledge, Attitudes, Practices and Needs-Responses from Second Round of Data Collection in Five Nairobi Informal Settlements (Kibera, Huruma, Kariobangi, Dandora, Mathare). Poverty, Gender, and Youth, 2020. https://doi.org/10.31899/ pgy14.1013.

67. ReliefWeb. Rapid Gender Analysis - COVID-19: West Africa - April 2020 - Benin. 2020. https://reliefweb.int/report/benin/rapid-gender-analy sis-covid-19-west-africa-april-2020.

68. Semaan AT, Audet C, Huysmans E, Afolabi BB, Assarag B, Banke-Thomas A, Blencowe H, Caluwaerts S, Campbell OM, Cavallaro FL, Chavane L. Voices from the frontline: findings from a thematic analysis of a rapid online global survey of maternal and newborn health professionals facing the COVID-19 pandemic. BMJ Global Health. 2020;5(6):e002967. https://doi.org/10.1136/bmjgh-2020-002967.

69. Coxon K, Turienzo CF, Kweekel L, Goodarzi B, Brigante L, Simon A, Lanau $\mathrm{MM}$. The Impact of the Coronavirus (COVID-19) pandemic on maternity care in Europe. Midwifery. 2020;88:102779-102779. https://doi.org/10. 1016/j.midw.2020.102779.

70. Ayenew B, Pandey D, Yitayew M, Etana D, Binay Kumar P, Verma N. Risk for Surge Maternal Mortality and Morbidity during the Ongoing Corona Virus Pandemic. Med Life Clin. 2020;2(1):1012.

71. Stevis-Gridneff M, Alisha HG, Monica P. Oronavirus Created an Obstacle Course for Safe Abortions. New York TImes. 2020. https://www.nytimes. com/2020/06/14/world/europe/coronavirus-abortion-obstacles.html.

72. Sobel L, Ramaswamy A, Frederiksen B, Salganicoff A. State Action to Limit Abortion Access During the COVID-19 Pandemic. KFF(blog), 2020. https://www.kff.org/coronavirus-covid-19/issue-brief/state-action-tolimit-abortion-access-during-the-covid-19-pandemic/.
73. UNFPA. Impact of the COVID-19 Pandemic on Family Planning and Ending Gender-Based Violence, Female Genital Mutilation and Child Marriage. UNFPA, 2020.

74. Federation, International Planned Parenthood. COVID-19 Pandemic Cuts Access to Sexual and Reproductive Healthcare for Women around the World. News Release. Published Online April 9, 2020, n.d.

75. Jeffrey G, Raj S. 8 Hospitals in 15 Hours: A Pregnant Woman's Crisis in the Pandemic." New York Times. 2020. https://www.nytimes.com/ 2020/06/21/world/asia/coronavirus-india-hospitals-pregnant.html.

76. Kumari V, Mehta K, Choudhary R. COVID-19 outbreak and decreased hospitalisation of pregnant women in labour. Lancet Global Health. 2020;8(9):e1116-7. https://doi.org/10.1016/S2214-109X(20)30319-3.

77. Takemoto ML, Menezes MO, Andreucci CB, Knobel R, Sousa L, Katz L, Fonseca EB, Nakamura-Pereira M, Magalhães CG, Diniz CS, Melo AS. Clinical characteristics and risk factors for mortality in obstetric patients with severe COVID-19 in Brazil: a surveillance database analysis. BJOG. 2020. https://doi.org/10.1080/14767058.2020.17860 56.

78. Rafaeli T, Hutchinson G. The Secondary Impacts of COVID-19 on Women and Girls in Sub-Saharan Africa, (n.d.). Resource Centre. Retrieved December 29, 2020, from https://resourcecentre.savet hechildren.net/node/18153/pdf/830_covid19_girls_and_women_ ssa.pdf

79. Khalil A, Von-Dadelszen P, Draycott T, Ugwumadu A, O'Brien P, Magee $L$. Change in the incidence of stillbirth and preterm delivery during the COVID-19 Pandemic. JAMA. 2020;324(7):705-6. https://doi.org/10.1001/ jama.2020.12746.

80. KC, A., Gurung, R., Kinney, M. V., Sunny, A. K., Moinuddin, M., Basnet, O., Paudel, P., Bhattarai, P., Subedi, K., Shrestha, M. P., Lawn, J. E., \& Målqvist, M. Effect of the COVID-19 pandemic response on intrapartum care, stillbirth, and neonatal mortality outcomes in Nepal: A prospective observational study. Lancet Global Health. 2020;8(10):e1273-81. https:// doi.org/10.1016/S2214-109X(20)30345-4.

81. Been JV, Ochoa LB, Bertens LC, Schoenmakers S, Steegers EA, Reiss IK. Impact of COVID-19 mitigation measures on the incidence of preterm birth: A national quasi-experimental study. MedRxiv. 2020. https://doi. org/10.1101/2020.08.01.20160077.

82. Shuchman M. Low-and middle-income countries face up to COVID19. Nature Medicine. 2020;26(7):986-8. https://doi.org/10.1038/ d41591-020-00020-2.

83. Bong CL, Brasher C, Chikumba E, McDougall R, Mellin-Olsen J, Enright A. The COVID-19 pandemic: effects on low-and middle-income countries. Anesthesia Analgesia. 2020. https://doi.org/10.1213/ANE.0000000000 004846.

84. Hupkau C, Petrongolo B. COVID-19 and Gender Gaps: Latest Evidence and Lessons from the UK. VoxEU. Org22. 2020.

85. Boniol M, Mclsaac M, Xu L, Wuliji T, Diallo K, Campbell J. Gender equity in the health workforce: Analysis of 104 countries, viewed 27 April 2020. 2019. https://apps.who.int/iris/bitstream/handle/10665/311314/WHOHIS-HWF-Gender-WP1-2019.1-eng.pdf? sequence=1\&isAllowed=y

86. Robertson C, Gebeloff R. How Millions of Women Became the Most Essential Workers in America. The New York Times, 2020. https://www. nytimes.com/2020/04/18/us/coronavirus-women-essential-workers. html.

87. Jankowski J, Davies A, English P, Friedman E, McKeown H, Rao M, Sethi S, Strain WD. Risk Stratification for Healthcare Workers during CoViD19 Pandemic: Using Demographics, Co-Morbid Disease and Clinical Domain in Order to Assign Clinical Duties. Medrxiv. 2020.

88. World Health Organization. Shortage of Personal Protective Equipment Endangering Health Workers Worldwide. World Health Organization. 2020. https://www.who.int/news-room/detail/03-03-2020-shortageof-personal-protective-equipment-endangering-health-workers-world wide.

89. Alon TM, Doepke M, Olmstead-Rumsey J, Tertilt M. The Impact of COVID-19 on Gender Equality. National Bureau of Economic Research, 2020.

90. Johnston RM, Mohammed A, van der Linden C. Evidence of exacerbated gender inequality in child care obligations in Canada and Australia during the COVID-19 pandemic. Politics Gender. 2020. https:// doi.org/10.1017/S1743923X20000574. 
91. Malik S, Naeem K. Impact of COVID-19 Pandemic on Women: Health, livelihoods \& domestic violence. Sustainable Development Policy Institute. 2020. http://www.jstor.com/stable/resrep24350

92. UN Women. The Private Sector's Role in Mitigating the Impact of COVID-19 on Vulnerable Women and Girls in Nigeria. 2020. https:// www.weps.org/resource/private-sectors-role-mitigating-impact-covid19-vulnerable-women-and-girls-nigeria

93. Wahome C. Impact of Covid-19 on Women Workers in the Horticulture Sector in Kenya. Hivos. 2020. https://www.hivos.org/assets/2020/05/ Hivos-Rapid-Assessment-2020.pdf

94. World Vision International Cambodia. Rapid Assessment of the impact of COVID-19 on child wellbeing in Cambodia Summary Report. 2020. https://www.wvi.org/publications/cambodia/rapid-assessment-summa ry-report-impact-covid-19-childrens-well-being-cambodia

95. Staff of the National Estimates Branch. Current Employment Statistics Highlights. U.S. Bureau of Labor Statistics, 2020. https://www.bls.gov/ web/empsit/ceshighlights.pdf.

96. Adams-Prassl A, Boneva T, Golin M, Rauh C. Inequality in the Impact of the Coronavirus Shock: Evidence from Real Time Surveys. IZA Discussion Papers. 2020. https://www.iza.org/publications/dp/13183/inequ ality-in-the-impact-of-the-coronavirus-shock-evidence-from-real-timesurveys

97. Novel Coronavirus (COVID-19): Violence, Reproductive Rights and Related Health Risks for Women, Opportunities for Practice Innovation. 2020 https://www.ncbi.nlm.nih.gov/pmc/articles/PMC7275128/

98. Wanqing Z. Domestic Violence Cases Surge During COVID-19 Epidemic. Sixth Tone, 2020. https://www.sixthtone.com/news/1005253/domesticviolence-cases-surge-during-covid-19-epidemic.

99. Euronews. Domestic Violence Cases Jump 30\% during Lockdown in France. euronews, 2020. https://www.euronews.com/2020/03/28/ domestic-violence-cases-jump-30-during-lockdown-in-france.

100. Women, U. N. COVID-19 and Ending Violence against Women and Girls. New York. 2020

101. Sigal L, Ramos Miranda NA, Martinez Al, Machicao M.Another Pandemic: In Latin America, Domestic Abuse Rises amid Lockdown. Reuters, 2020. https://www.reuters.com/article/us-health-coronaviruslatam-domesticviol/another-pandemic-in-latin-america-domesticabuse-rises-amid-lockdown-idUSKCN2291JS.

102. Graham-Harrison E, Giuffrida A, Smith H, Ford L. Lockdowns around the World Bring Rise in Domestic Violence. The Guardian. 2020, sec. Society. https://www.theguardian.com/society/2020/mar/28/lockdowns-worldrise-domestic-violence.

103. Bosman J. Domestic Violence Calls Mount as Restrictions Linger: 'No One Can Leave. New York Times. 2020. https://www.nytimes.com/2020/ 05/15/us/domestic-violence-coronavirus.html.

104. Women's Safety NSW. "New Domestic Violence Survey in NSW Shows Impact of COVID-19 on the Rise." Women's Safety NSW, April 3, 2020. https://www.womenssafetynsw.org.au/wp-content/uploads/2020/04/ 03.04.20_New-Domestic-Violence-Survey-in-NSW-Shows-Impact-ofCOVID-19-on-the-Rise.pdf.

105. Biaggi A, Conroy S, Pawlby S, Pariante CM. Identifying the women at risk of antenatal anxiety and depression: a systematic review. J Affect Disord. 2016:191:62-77. https://doi.org/10.1016/j.jad.2015.11.014.

106. Kaur R, Garg S. Addressing domestic violence against women: an unfinished agenda. Indian J Commun Med. 2008;33(2):73-6. https://doi.org/ 10.4103/0970-0218.40871.

107. Dennis CL, Vigod S. The relationship between postpartum depression, domestic violence, childhood violence, and substance use: epidemiologic study of a large community sample. Violence Against Women. 2013 Apr;19(4):503-17. https://doi.org/10.1177/1077801213487057.

108. Kem J. Framework in Ending Violence Against women and Girls with the Advent of the COVID 19 from an African Perspective. 2020. Available at SSRN 3575288.

109. Mukherjee S, Dasgupta P, Chakraborty M, Biswas G, Mukherjee S. Vulnerability of Major Indian States Due to COVID-19 Spread and Lockdown. 2020.

110. Carter Ebony B, Tuuli Methodius G, Caughey Aaron B, Odibo Anthony O, Macones George A, Cahill Alison G. Number of prenatal visits and pregnancy outcomes in low-risk women. J Perinatol. 2016;36(3):178-81. https://doi.org/10.1038/jp.2015.183.
111. Gajate-Garrido G. The impact of adequate prenatal care on urban birth outcomes: an analysis in a developing country context. Econ Dev Cult Change. 2013;62(1):95-130. https://doi.org/10.1086/671716.

112. Panagiotakopoulos $L$. SARS-CoV-2 infection among hospitalized pregnant women: Reasons for admission and pregnancy characteristics-Eight US health care centers, March 1-May 30, 2020. Morbidity and Mortality Weekly Report: MMWR; 2020. p. 69.

\section{Publisher's Note}

Springer Nature remains neutral with regard to jurisdictional claims in published maps and institutional affiliations.
Ready to submit your research? Choose BMC and benefit from:

- fast, convenient online submission

- thorough peer review by experienced researchers in your field

- rapid publication on acceptance

- support for research data, including large and complex data types

- gold Open Access which fosters wider collaboration and increased citations

- maximum visibility for your research: over $100 \mathrm{M}$ website views per year

At BMC, research is always in progress.

Learn more biomedcentral.com/submissions 